\title{
"Count on me!"
}

\section{Mathematical development, developmental dyscalculia and computer-based intervention}

\author{
Linda Olsson
}

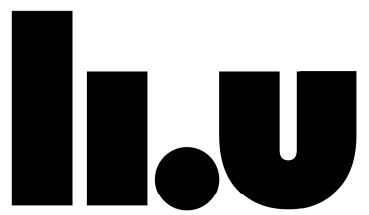

LINKÖPING UNIVERSITY

Linköping Studies in Arts and Science No 728

Linköping Studies in Behavioural Science No 204 Linköping 2018 
Linköping Studies in Arts and Science No 728

Linköping Studies in Behavioural Science No 204

At the Faculty of Arts and Sciences at Linköping University, research and doctoral studies are carried out within broad problem areas. Research is organized in interdisciplinary research environments and doctoral studies mainly in graduate schools. Jointly, they publish the series Linköping Studies in arts and Science. This thesis comes from the Division of psychology at the Department of Behavioral Sciences and Learning.

Distributed by:

Department of Behavioral Sciences and Learning

Linköping University

58183 Linköping, Sweden

Linda Olsson

"Count on me!"

Mathematical development, developmental dyscalculia and computer-based intervention

Edition 1:1

ISBN 978-91-7685-409-9

ISSN 0282-9800

ISSN 1654-2029

\section{CLinda Olsson}

Department of Behavioral Sciences and Learning, 2018

Cover illustration: Linda Olsson

Printed by: LiU-Tryck, Linköping, 2017 


\begin{abstract}
A "sense" of number can be found across species, yet only humans supplement it with exact and symbolic number, such as number words and digits. However, what abilities leads to successful or unsuccessful arithmetic proficiency is still debated. Furthermore, as the predictability between early understanding of math and later achievement is stronger than for other subjects, early deficits can cause significant later deficits. The purpose of the current thesis was to contribute to the description of what aspects of non-symbolic and symbolic processing leads to later successful or unsuccessful arithmetic proficiency, and to study the effects of different designs of computer-programs on pre-school class aged children. The cognitive mechanisms underlying symbolic number processing and different arithmetic skills were mapped to discover their contributions to children's proficiency. Findings show that the non-symbolic system continues to contribute to arithmetic performance, and that the general cognitive abilities' contributions might vary with development. Moreover, more advanced mathematical skills were supported by less advanced. In order to investigate the underlying core deficit in DD, performance was contrasted with an individually matched control group on general cognitive abilities. Findings indicate that DD children are impaired on both nonsymbolic and symbolic processing, the most impairment on the symbolic measures. Furthermore, the results indicated subgroups. In order to investigate the effects of early intervention, three theoretically different designs of computer programs, designed in accordance to hypotheses of number processing were compared to a passive control group. Results revealed that even brief, daily arithmetic training utilizing theoretically different designs impacted different aspects of symbolic processing. The presented findings indicate that the non-symbolic system is the foundation for the symbolic system, and that DD is caused by a non-symbolic deficit. The present thesis also adds evidence that formal arithmetic is founded on precise representations, rather than approximate.
\end{abstract}




\section{Sammanfattning på svenska}

En "känsla" för antal finns hos flera arter, men enbart människan berikar denna med ett exakt och symboliskt system, t.ex. siffror. Det debatteras dock fortfarande vilka kognitiva förmågor som leder till mer eller mindre lyckad aritmetisk förmåga. Förutsägbarheten mellan tidig förståelse och senare matematikförmåga är dessutom starkare än för andra skolämnen. Tidiga nedsättningar kan således orsaka senare signifikanta nedsättningar. Syftet med avhandlingen var att bidra till beskrivningen av vilka aspekter av icke-symboliskt och symboliskt processande som bidrar till aritmetisk förmåga, samt att studera effekterna av olika teoretiskt designade datorbaserade träningsprogram på förskoleklassbarn.

De kognitiva mekanismerna som ligger till grund för symboliskt nummerprocessande och olika aritmetiska förmågor kartlades för att upptäcka deras respektive bidrag hos barn med relativt välutvecklade symboliska system. Fynden visar att det icke-symboliska systemet fortsätter att bidra till aritmetik, och att de domän-generella kognitiva förmågornas bidrag kan variera med utveckling. Därtill, mer avancerade matematiska förmågor stöddes av mindre avancerade. I syfte att undersöka dyskalkylis underliggande orsak jämfördes dessa barn med en kontrollgrupp, individuellt matchad på domän-generella kognitiva förmågor. Resultaten visar att barnen med dyskalkyli uppvisade nedsättning på såväl icke-symboliska som symboliska mått, men störst nedsättning på de symboliska. Därtill indikerade resultatet subgrupper. I syfte att undersöka effekterna av tidig intervention jämfördes tre datorprogram, olikt designade i enlighet med nummerprocessande, med en passiv kontrollgrupp. Till och med kort, daglig aritmetisk träning gav effekt. De teoretiskt olika datorprogrammen påverkade olika symboliska mått. Avhandlingen indikerar att det icke-symboliska systemet ligger till grund för det symboliska, och att dyskalkyli orsakas av en icke-symbolisk nedsättning. Avhandlingen stödjer att formell aritmetik grundas på exakta representationer, snarare än approximativa. 


\section{List of papers}

I. Träff, U., Olsson, L., Skagerlund, K., \& Östergren, R. Cognitive Mechanisms Underlying Third Graders' Arithmetic Skills: Expanding the Pathways to Mathematics Model. (In press) Journal of Experimental Child Psychology. Doi: 10.1016/j.jecp.2017.11.010

II. Olsson, L., Östergren, R., \& Träff, U. Devlopmental Dyscalculia; a deficit in the approximate number system or an access deficit? (2016) Cognitive development, 39, 154-167. Doi: 10.1016/j.cogdev.2016.04.006

III. Olsson, L., \& Träff, Computer-assisted training in the pre-school class. Under review. 



\section{Acknowledgement}

I strongly believe that things happen for a reason. Roughly six years ago, I was completing my psychologist's licence and had not really started thinking much about the future. Then I got an e-mail from out of the blue, asking if I would be interested in becoming a PhD student. Since then, time has passed sort of in a blur. However, the present thesis did not just "happen". I owe my gratitute to a lot of people in this world, and the thesis would not exist for many of the following people.

First of all, my sincearest gratitude to my main supervisor Ulf Träff. You have been a great support system and discussion partner in planning and designing the study/studies. You have given me much freedom to do what I wanted and provided me with much advice over the years. Even though I am (most of the time) quite headstrong and stubborn, you have managed to (at least sometimes) sway my opinions and guide me.

To my other supervisor, Joakim Samuelsson, thank you for signing my papers and for having answers regarding the pedagogical aspects of the school system which I have little insight into.

A great big thank you to my, in my mind "honorary supervisor", Rickard Östergren! Thank you for "luring" me into this world roughly 8 years ago! Had it not been for your enthusiasm and genuine interest, I do not believe I would be here today.

I also owe a great deal of gratitude to the designer of the computer program, Eriks Zaharans. Without your ideas and great design I am certain I would not have managed to get as many effects. After taking that course in computer databases I have greater understanding for your amused look when I could not give you any specifics.

I am also incredibly grateful to all my past and present colleages at Linköping University. You are too many to thank individually and I am afraid I could fill an entire other thesis with all of your names and would still risk to forget to name all of you! THANK YOU! The "old foxes" of PhD life Josefine Andin, Emelie Nordqvist, Cecilia Henricsson, Elaine $\mathrm{Ng}$, etc. Thank you for all the advice along the way and for giving me hope that there is life after the PhD! Elaine, thanks for the inspiration to "fly" and all your sage advice. Special thank you Josefine, for giving me hope that designing the cover of the thesis was not as difficult as it seemed. Emelie, for giving me perspective and for understanding that sarcasm IS a language! Cecilia, we worked together in two worlds for a while and I am forever grateful to you for hooking me up with such an amazing other job! 
A very special thank you to all the participants and schools that has helped my research over the years. Although my tasks were not always fun, all of you kids always made my job so much better. I can not imagine having more fun while working! I hope to have made a difference for at least a few of you! (And YES, I am from Sweden!) Another special thank you goes to my amazing other job for the past two years, Barn- och ungdomshabiliteringen in Västervik. You guys have been such an amazing other job to go to recover and re-fuel my "creativity tank"! For also giving me perspective into what really matters, all of my former patients!

And finally, to my mom, dad and my brother; thank you! For listening to my rants, my (more than usual) indescision, and my mom for pushing me into the $\mathrm{PhD}$-life with a pitchfork. My dad's very sane voice in my head helping me to think rationally. My brother for always trying to keep me grounded, in more than one way...

Ja viimeks, Mummille, vaikka minusta ei tulee lääkäri, minusta tulee (kohta) tohtori! Kiitos kaikista, ja mulla on ikävä sinua yhä. 
Table of contents

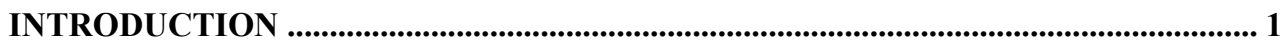

PURPOSE AND AIMS................................................................................................. 2

DEVELOPMENT OF NON-SYMBOLIC NUMBER ............................................................. 3

THE CORE NUMBER SYSTEMS............................................................................... 3

The approximate number system (ANS) ............................................................... 3

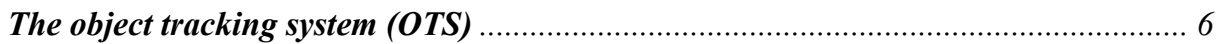

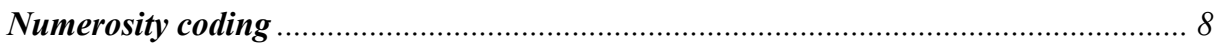

THE SYMBOLIC (NUMBER) SYSTEM ……....................................................................... 9

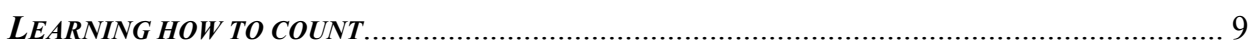

THE ROLE OF THE CORE SYSTEMS IN ACQUISITION OF THE SYMBOLIC SYSTEM ................... 10

ARITHMETIC ..................................................................................................................... 12

THE HIERARCHICAL NATURE OF MATH ................................................................... 13

WHAT PREDICTS FUTURE MATH ACHIEVEMENT: PATHWAYS TO

MATHEMATICS ……………………......................................................................................... 14

DEVELOPMENTAL DYSCALCULIA ............................................................................. 19

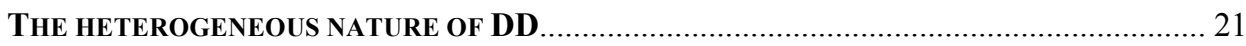

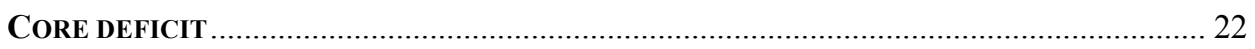

COMPUTER-BASED INTERVENTIONS ..................................................................... 26

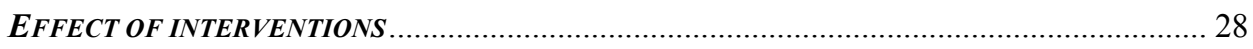

SPECIFIC AIMS .................................................................................................................... 31

EMPIRICAL STUDIES ...................................................................................................... 33

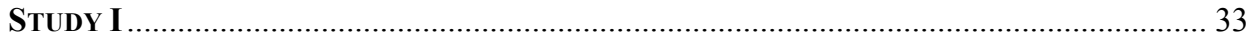

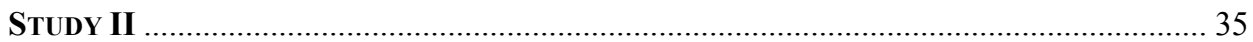

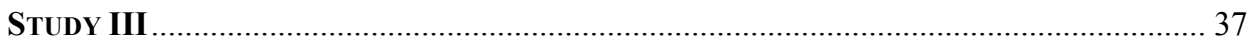

GENERAL DISCUSSION ........................................................................................................ 39

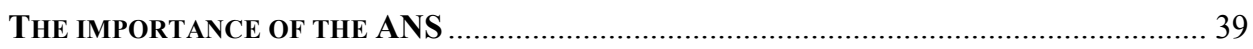

THE LANGUAGE-BASED, SYMBOLIC NUMBER SYSTEM................................................... 43

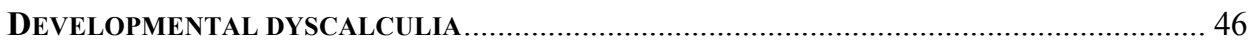

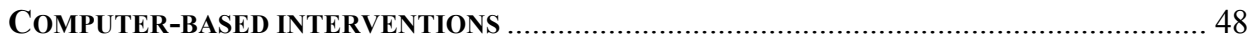


CONCLUSION

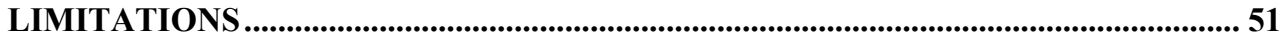

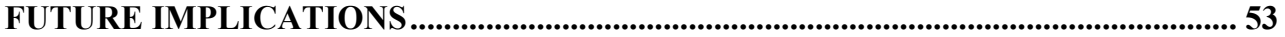

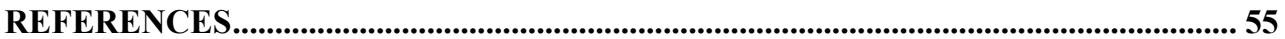




\section{Introduction}

Western society contains digits and number almost everywhere, on billboards, street signs and stores are filled with them. Furthermore, we are required to be able to tell time, know how much money is needed to purchase food and so forth to be able to function in our society. We are never more aware of our abilities to estimate, calculate and understand number as when we are tourists in a culture that does not use the same currency or does not use the same symbols. Suddenly, we do not know how much a piece of fruit costs in the supermarket. Is it expensive or cheap? How much money should I expect in change? We automatically use calculations to understand our new world.

While a "sense" of number can be found across animal species on the planet (Agrillo, Piffer, Bisazza, \& Butterworth, 2012), most human societies supplement this sense with exact and symbolic number, such as number words and digits. While attempts have been made to teach non-human monkeys number words, through sign language and digits, they fail to use the symbols spontaneously, fluently and flexibly (Cantlon \& Brannon, 2007b). Thus, suggesting the ability for a symbolic and exact number system is a uniquely human capability. However, what abilities and/or mechanisms support the development of the fundamental, underlying, comprehension of number into a symbolic, exact system is still debated. Furthermore, there is still debate as whether the fundamental aspects continue to impact the symbolic, exact system or not after it has been acquired. We also know that domain-general cognitive abilities such as aspects of working-memory, contribute to the development of arithmetic proficiency. However, it remains unclear what their roles are and what aspects of number they support.

Cross-cultural research has shown that most children from numerate societies are capable of performing basic addition and subtraction, even prior to formal education (Aunio, Korhonen, Bashash, \& Khoshbakht, 2014). However, there is also large individual variation in mathematical comprehension and performance. While some children consistently excel at mathematics (Brody \& Mills, 2005), others struggle with learning even the most fundamental aspects of symbolic number and later arithmetic despite adequate education and effort. Developmental dyscalculia, a pervasive learning disorder, causes severe mathematical difficulties in an estimated 5-6\% of the population. Despite causing significant impairment, the core deficit of the disorder is yet to be determined. Furthermore, entry-level mathematics 
in elementary school is predictive of later achievement on standardized tests (Duncan et al., 2007) and children of low mathematical ability before elementary school keep struggling with mathematics (Aunio, Heiskari, Van Luit, \& Vuorio, 2015; Desoete \& Grégoire, 2006). Thus, early intervention is key to prevent future mathematical difficulties, as level of math proficiency has been associated with successful employment and further, a higher income when employed (Dougherty, 2003; Rivera-Batiz, 1992) and influences personal debt (Gerardi, Goette, \& Meier, 2013).

\section{Purpose and aims}

The overall aim of the thesis is to contribute to the description of what aspects of early number and symbolic number processing may lead to later (successful or unsuccessful) mathematical proficiency, and to study the effects of differently designed computer-based programs, designed in accordance with influential models of the core number system. Domain-general cognitive abilities have been found to contribute to mathematical performance, their role was thus also examined. In order to describe early mathematical ability, I aim to study the domain general and specific cognitive mechanisms underlying symbolic processing and their interactions. I aim to utilize the combined knowledge in order to attempt to help us better understand the underlying mechanisms behind mathematics.

What characterizes the endowed non-symbolic ability and in what way does it enable humans to learn symbolic aspects of number, such as number words and digits? What role does the non-symbolic system play in children's continued development? What underlying deficit(s) leads to difficulties for some children to learn adequate arithmetic skills, despite adequate education and effort? While the current thesis cannot answer all of these questions, the knowledge from educationally experienced children who are arithmetically proficient will provide a description of more (study I) or less arithmetically proficient (study II), while the theoretically designed computer-based programs will be used to intervene early, already in the preschool class (study III). As the cost of being less mathematically competent is high, both for the individual and for our society, hopefully the current thesis will contribute to providing more scientifically evaluated computer-based interventions for non-selected children. How can we best intervene to support the development of arithmetic and mathematical abilities, to prevent suffering and the loss of/lower mathematical proficiency in the future? 


\section{Development of non-symbolic number}

While researchers agree on the existence of a non-verbal number system, there are competing theories as to how it is hypothetically structured. This thesis primarily deals with two main theories, the hypothesis of a core system, comprised of the approximate number system (ANS) and/or a parallel individuation system/object tracking system (OTS), and the alternative hypothesis of numerosity coding. While the theories differ in several aspects, they share some underlying assumptions. Both theories agree that this core ability/foundational capacity for number is genetically inherited, and grounded in neurological circuits specifically responsible for number. Research has indeed identified an area in the parietal lobe, the horizontal segments of the parietal sulcus of both hemispheres (hIPS), responsible for numerical quantities (Dehaene, Piazza, Pinel, \& Cohen, 2003). Furthermore, different regions activate for non-symbolic number and symbolic number (Roggeman, Verguts, \& Fias, 2007).

\section{The core number systems}

Dehaene (2001) defines number sense as the human brain's ability to mentally represent and manipulate quantities, due to areas of the brain dedicated to number. This ability is inherited, which explains the ability's presence in other animal species (Dehaene, 2001). Furthermore, its' presense in other animal species also indicate the ability is not due to cultural transmission, through for example language nor individual learning (Feigenson, Dehaene, \& Spelke, 2004). Theoretically, this ability is based on two distinct core systems: the approximate number system (ANS) and the object tracking system (OTS). These systems are non-verbal in nature and are non-exact, thus noisy.

\section{The approximate number system (ANS)}

A "sense" of number can be found in several animal species, besides humans (cf. Agrillo et al., 2012; Cantlon \& Brannon, 2007a). This ability is dependent on the ratio or difference between numerosities, and becomes apparent when making approximations and comparisons between objects, sounds or amounts. The guppy fish in Agrillo et al., (2012) chose the larger of two shoals, containing more other fish, at similar ratios as human graduate students chose between two dot arrays. While this ability is restricted in non-human species, the ability sharpens with development in humans. Newborns have the ability to connect the amount of sounds to visuo-spatial arrays (4-18 objects) (Izard, Sann, Spelke, \& Streri, 2009). While 
human infants are able to discriminate between visual (dot) arrays and auditory (sound sequences) stimuli at ratios of 1:2, already at six-months of age (Lipton \& Spelke, 2003). The acuity or sharpness of the ability rapidly develops. Already at nine-months of age, infants can discriminate at ratios of 2:3, for example twelve from eight sounds (Lipton \& Spelke, 2003). Thus, occurring before language has emerged or number words/counting have gained meaning. This ability continues to sharpen, pre-school children can discriminate at ratios at $3: 4$, and is at its most precise around 20 -years of age, when discrimination is "stable" at ratios of $7: 8$, to later decline.

The ANS handles larger approximate representations of number, organized/handled through a mental number line. On this line, numerosity is mapped with coordinating visuo-spatial properties nonverbally (De Hevia, Girelli, \& Vallar, 2006). Each number is thus related to a spatial location (De Hevia et al., 2006). With the aid of this number line, humans can mentally represent and manipulate numerosities. The representations of the ANS are intermodal, meaning visual and auditory.

The most compelling evidence for the mental number line's organization is the SpatialNumeric Automatic of Response Codes (SNARC) effect, larger number is associated with the right side and small number to the left, or vice versa. The SNARC effect has been found to depend on the reading/writing direction of the individual's native tongue (Dehaene, Bossini, \& Giraux, 1993), as people who adopt a second language with the opposite reading/writing direction later in life show a decreased SNARC effect. This indicates that the direction of the number line is aquired during school years (De Hevia, Girelli, Bricolo, \& Vallar, 2008) or is influenced by culture. Furthermore, the SNARC effect does not depend on handedness. The effect also continues into double-digits, but has also been reported with months, letters and so forth (Dehaene et al., 1993).

Further evidence of the organization of the number line is the distance and size/magnitude effect. Humans are faster at identifying the numerically larger digit when the digits are small, for example single-digits (size effect) (e.g., 1 vs $2 ; 10$ vs. 11). It is also perceived as easier to distinguish between digits when they are more numerically distant from each other (distance effect), as the time needed to compare the digits decreases as their distance increases (Moyer \& Landauer, 1967). Thus, making it easier to distinguish between (1 vs. 10) than (1 vs. 3 ). The distance effect is visible already in five-year-old children, thus before digits are fully 
automatized. The effect decreases over development, as older children and adults have shallower reaction time slopes. According to the ANS hypothesis, the smaller the distance effect, the more distinct are the underlying representations, making them more distinguishable and results in faster reaction times.

The representations of the mental number line are hypothetically compressed, and the relationship between reality/stimulus and the internal representations can best be explained either by logarithmic or linear relationship (Piazza, 2011). The linear model assumes equal distances between the magnitude representations, but the resolution becomes fuzzier with increasing size. Thus, more errors/misreads occur towards greater amounts/magnitudes than smaller. The logarithmic compression assumes larger differentiability between the smaller magnitudes, as their distances are larger, whereas the distance between the larger magnitudes is perceived as smaller. However, both models assume that with increasing size, the magnitudes will overlap more, which explains the greater imprecision with size (Feigenson et al., 2004). There is also speculation that the ANS is logarithmically compressed and humans learn to compensate with age and/or education, explaining why adult performance becomes increasingly linear (Siegler \& Opfer, 2003). It might also explain why humans can process multiple representations on the mental number line (Ashkenazi \& Henik, 2010).

While compression of the ANS is assumed, there are individual differences in the precision of these underlying representations compared to the actual amounts. The ratio which determines how sensitive one's comparisons are obey the Weber-Fechner law, describing the relationship between the physical and the perceived magnitude of a stimulus. The Weber Fraction (w) measures the smallest numerical change to a stimulus which can be reliably detected. A wscore close to zero approaches the true value of the numerosity presented and increases in precision during development, being fully developed around 20-years of age. This so-called acuity varies across individuals (Inglis \& Gilmore, 2014). The individual acuity has led to a speculation of different implications. Piazza, Pica, Izard, Spelke, \& Dehaene, (2013) suggests that ANS acuity increases as a result of education, and not (biological) maturity. Furthermore, some research has implicated that ANS acuity correlates with knowledge of exact (symbolic) number (Mussolin, Nys, Leybaert, \& Content, 2012). Starr, Libertus, \& Brannon, (2013) found ANS acuity at six months of age correlated standardized math scores and non-symbolic comparison scores at three and a half years-of age, while Purpura and Logan (2015) found a nonlinear relationship between the ANS, mathematical language and mathematical 
performance, suggesting the importance of the ANS differs (due to differing predictability) at different time points in development. A possible explanation for the differing results could be the method used to assess the acuity of the ANS. There are no agreed upon guidelines (for method) to tap the ANS. Usually, subjects are shown two arrays of dots either next to each other, serially or sequentially (Clayton, Gilmore, \& Inglis, 2015). A common method to show the arrays is through the computer program Panamath, which generates a measure of $w$, accuracy and answering speed (Halberda \& Feigenson, 2008). Negen and Sarnecka (2015) argue the previously found correlations are due to methodological issues. According to the authors, size and number were not controlled for in previous studies, causing false positives. Further evidence was provided by Clayton et al., (2015). By using two different (computer) scripts for the computer program Panamath, the results yielded poor correlations between differing size/area controls and reliability.

\section{The object tracking system (OTS)}

Humans also possess a system for handling small sets (1-4) of objects, called the object tracking system (OTS) or parallel individuation system (Feigenson et al., 2004). The OTS is considered a domain general ability, reflecting/utilizing an aspect of working-memory, unlike the ANS. The OTS allows the individual to track small numbers of items across time and space (Piazza, Fumarola, Chinello, \& Melcher, 2011), by assigning tags to individual items. These assigned tags allow for simple addition and subtraction, which is evident in habituation studies in infants who look longer at solutions containing errors. Similar to the ANS, the OTS is subject to maturation. Infants are initially restricted to a single object, and reach full capacity around the first year of life (Piazza, 2011).

The OTS is primarily evident in tasks tapping subitizing, the accurate and immediate recognition of numerosities up to four objects. Subitizing occurs even when items are masked and with brief demonstrations. Arrays containing more than five objects show a marked increase in reaction time and errors, which is believed to be signs of effortful counting, so called enumeration. The increase in reaction time is believed to be due to the one-to-one mapping between objects and number words (Schleifer \& Landerl, 2011). If enumeration/counting is prevented, the signature of the ANS and approximations (ratio dependency) becomes apparent. Furthermore, parallel research in the ocular attention field has shown that exact counting/enumeration fails if eye movements or are prevented or 
attention is occupied (Piazza \& Izard, 2009). Subitizing can also influence other tasks where pattern is not controlled for, called canonization. Some researchers also indicate there is a relationship between subitizing and visuo-spatial working memory (see Piazza et al., 2011).

Research has also shown an incompatibility between small and large sets, thus when the OTS and the ANS need to be deployed simultaneously. When infants were asked to compare between large arrays ( 8 vs. 16) the infants succeeded, but failed when one of the numerosities contained less than/or four objects ( 2 vs. 4 ) even though their ratio was identical to larger amounts of objects (Halberda \& Feigenson, 2008). When utilizing cross-modal methods, sounds and dots, infants successfully could discriminate two from three. However, infants still consistently fail to discriminate when the larger number in the set is larger than four. In contrast, adults successfully compare between smaller and larger numerosities and do not display the result pattern of infants. Hypothetically, the ANS has no lower bound and should theoretically also operate on small amounts. Additionally, as the representations of the ANS obey Weber's law, the smaller numerosities should be more easily distinguishable compared to larger ones. The question of whether subitizing is supported by the ANS, instead of being dependent on the OTS, has been tested in a study on adult participants (Revkin, Piazza, Izard, Cohen, \& Dehaene, 2008). The authors included number from 1-8 and 10-80, and the items were matched for size and distance effect. Enumeration/counting was prevented, subgrouping and arithmetic strategies. Results showed a clear violation of Weber's law, as precision was significantly higher in the small numbers range (1-4). Other studies have shown clear violations of Weber's law and ratio dependency, the ANS' signature. A possible explanation is that the OTS's representations are exact and discrete, and are thus more reliable for small values. Therefore, humans primarily utilize their OTS' for smaller numbers. Another hypothesis is that humans require time and experience to make the OTS and ANS compatible, thus deploying the core systems simultaneously and fluently.

Another possible explanation is that area/surface might influence infants' comparisons, and infants might simply have a perceptual preference for looking at "more". In some previous studies, six-month-old infants fail at discriminating small numerosities, if surface area and contour length are controlled for (Feigenson, Carey, \& Spelke, 2002). Thus, implying that changes in cumulative area are more important to infants than number per se. However, other studies have found the exact opposite (Brannon, 2002; Lipton \& Spelke, 2003). A possible explanation has been that infants' sensitivity to number differ depend on the array size. 
Feigenson et al., (2002) found that infants attended to number when the array size was small (in the OTS range) whereas when discriminating between larger arrays, the infants preferred area. Research has however found that infants can discriminate between 8 and 16 when confounding variables are controlled for (Brannon, Abbott, \& Lutz, 2004). Furthermore, the infants failed at identifying the same twofold increase in area, although the same ratio was utilized. Thus, showing little/no sensitivity to area changes and focused on number. Similar to humans, non-human primates show an overall bias towards number over cumulative surface area and numerical ratio effect both in small and large number ranges (Cantlon \& Brannon, 2007b). Hence, indicating an inherited shared ability/sensitivity to number rather than surface area, probably developed through evolution for survival.

\section{Numerosity coding}

Another similar theory of how number is represented is numerosity coding (Butterworth, 2010). The theory was originally developed as a neural network theory, designed to predict behavioral data. Similar to the theory of the core systems, numerosity coding is based on the hypothesis of neurological circuits specifically tuned for numerosity or that specific neurons code for numerosity. Accordingly, the neurons have a tuning function, and respond to a preferred value. The value can be plotted in function of numerosity. Thus, unlike the theory of core system(s) the numerosity coding assumes exact representations, each numerosity directly corresponding to a neural node (Zorzi, Stoianov, \& Umiltà, 2005). Furthermore, the theory assumes that non-symbolic and symbolic number map linearly onto the pre-existing magnitude representations. An analogy used to describe the theory is a thermometer; as the numerosity increases the smaller numerosities are encompassed in the larger numbers. Accordingly, exact number is mapped directly onto the neural nodes (non-verbal representations), with addition facts recorded as "non semantic verbal formulae". The theory predicts that impaired representations will affect addition (Butterworth, 2010). 


\section{The symbolic (number) system}

The systems or theories described above are all non-symbolic, thus non-exact. The ANS is only approximate, which is not practical when for example handling money, as this requires exact calculation. The OTS on the other hand, while exact, is only capable of representing magnitudes up to four. To compensate, humans in numerate societies developed/utilize external support (written symbols/digits) and a specific language for number to communicate number's exact and accurate values through number words (such as "three"), allowing communication of facts and properties. Some native/indigenous cultures, such as in the Amazon, do not have exact number words for amounts above four, instead having words like "five-ness"/more than four (Pica, Lemer, Izard, \& Dehaene, 2004). These small indigenous tribes fail to perform exact calculations, but can perform approximations similar to those of young children from numerate societies (Dehaene, Spelke, Pinel, Stanescu, \& Tsivkin, 1999; Pica, Lemer, Izard, \& Dehaene, 2004). Furthermore, as these societies do not have a counting sequence (“one, two, three...”) beyond four, these findings provide evidence of language's integral part of the development of the exact system, which requires time and, to some extent, effort. As the above described systems/theories (ANS, OTS and numerosity coding) are innate, detectable in early development before language is acquired, one line of research has focused on the process of how exact number develops and what part the underlying nonsymbolic system(s) play in exact number's development. While the above mentioned (nonsymbolic) theories slightly differ, they agree that this non-symbolic system develops into a symbolic system, capable of performing exact calculations and utilizing digits in numerate societies.

\section{Learning how to count}

Learning how to count is one of the first steps in developing a mature symbolic system, which can also be described as learning to associate an ordered sequence of count words with the corresponding numerosity. The seminal work of Gelman and Gallistel (1978) followed children's development of counting and the counting principles which children learned. The authors found that most children progress through a series of steps. Children first learn the list of count words/integer list by rote (one, two, three...), but the words lack meaning. Thereafter the children learn a counting procedure, by mapping items through one-one-correspondence; a number word will be associated with a specific number of items. Thereafter, children learn the cardinal meaning of the words, where only one count word can be applied to one item in a set 
(McCrink \& Wynn, 2007). In order to generalize the count sequence, the child must use the number words in the same sequence/order regardless of what is being counted, known as the fixed/stable-order principle. The final developmental step is knowing that the last count word used represents the entire set, all the items visible, known as the cardinal value. Children begin counting at around two-years-old, but the process to master counting lasts roughly an additional four years (Kamawar et al., 2010).

\section{The role of the core systems in acquisition of the symbolic system}

There are several hypotheses for the role of the core systems, the ANS and OTS, in the development of symbolic number described above (De Hevia et al., 2006; Le Corre \& Carey, 2007). One hypothesis is that exact number maps through the help of the OTS. Through visual working memory, the child can utilize the OTS' capacity to represent small, exact internal representations and compare them to real objects. Thus, each tag already assigned by the OTS will also contain a symbolic (number word) tag. This in turn helps the child realize the cardinal value. Another hypothesis is that only the ANS is used to map non-symbolic representations onto the symbolic, as children performing verbal (number words) estimates still show the signature of the ANS. The last hypothesis for the core systems' roles states that it is through combined insights systems, that leads the child able to grasp the counting principles and also exact symbolic, verbal understanding.

There has been speculation that the ANS acuity is sharpened by the acquisition of the symbolic system in a similarly reciprocal manner as phonological processing supports the acquisition of reading (e.g., Hogan, Catts, \& Little, 2005). Hypothetically, the non-symbolic representations aid the acquisition of the symbolic system, which in turn sharpens the ANS' representations. Evidence for the hypothesis has been put forth by several studies, showing that the exact, symbolic system impacts the non-symbolic. Le Corre and Carey (2007) found that children that had mastered the verbal count list, but not the counting principles (the last word used in the count sequence is the word representing the whole set) performed poorer on estimation (ANS) than children who had mastered the counting principles. Thus, showing that the exact, symbolic system can impact the precision in the underlying non-symbolic representations before formal education (Le Corre \& Carey, 2007). Another interpretation is that ANS acuity is related to educational experience and not (biological) maturity (Piazza et al., 2013). Recent findings on uneducated, limited education and educated individuals living 
in a numerate society (Portugal), showed large differences among the groups for both estimation, calculation and non-symbolic comparison tasks (Nys et al., 2013). The authors also showed that there was a potential impact of everyday use of numbers, although the uneducated group showed significantly less accurate/precise ANS'. Other findings (Libertus et al., 2011; Mazzocco et al., 2011) suggest that ANS acuity and mathematical ability are related before formal education. Thus, a sharper ANS will lead to a faster and more efficient mathematical ability.

There is however evidence that performing either non-symbolic comparison or non-symbolic addition impacted arithmetic performance in first-graders (Hyde, Khanum, \& Spelke, 2014). However, both tasks (comparison and addition) produced similar effects during brief training and immediate post-measurement. However, it was also shown that children who first performed non-symbolic approximate addition performed more accurately on exact, symbolic addition problems than the children who performed a brightness magnitude comparison task (Hyde et al., 2014). Similar experiments where pre-school aged (5-year old) children were shown increasingly difficult trials of non-symbolic comparison, unlike the standard random order, were also influenced on a symbolic math task performed afterwards (Wang, Geng, Hu, Du, \& Chen, 2013).

One of the most influential models/theories describing how number and numerical processing develops and is handled is the Triple-code model (Dehaene, 1992). It is based on three fundamental hypotheses. The first hypothesis is that numerical information can be (mentally) manipulated in three different formats, non-symbolic, visual (digit) and verbal (number words). These formats form a respective code, for example the non-symbolic code contains analogical representations of quantities, where number is represented as activations on the number line. The verbal code represents number as strings of words, and is responsible for rote memorization of arithmetic facts and multiplication tables, memorized as verbal associations between numbers as words. The visual, Arabic code contains the digits as a string, and supports multi-digit operations. The second hypothesis is that humans can transcode from one code to another and the numerosity/numeral will remain the same, nothing lost in conversion. The third and last hypothesis is that calculation rests on a fixed set of inputs and outputs, in a number comparison task the input is quantities on the number line (Dehaene, 1992). 
The developmental model of von Aster and Shalev (2007) details the steps of children's acquisition of the exact, symbolic aspects of number in a hierarchical model. The authors include the previously described core systems as the foundation for the other aspects of number. Children learn symbolic number by associating objects/magnitudes firstly with number words, such as “one” with “*”. If the child does not have precise/correct magnitude representations, the number words will lack underlying meaning and will only be learned by rote. Thus, explaining why children in early development will recite the count sequence but are unable to start from a given number. When the connection between number words and the associated amount is complete, the child will connect the number words to their digit equivalent (the child will equivalate "three" with " 3 "). Afterwards, in the last and final step the child will develop an automatized spatial image of ordinal numbers on a number line, where number is associated with a spatial location and with numerical neighbors. Von Aster and Shalev (2007) also point out that this mental representation can consist of other synesthetic, such as colors, sound and brightness.

\section{Arithmetic}

While the ability to make approximations and comparisons is shared with many animal species, the ability to perform (advanced) calculations spontaneously is a uniquely human ability. Evidence of the (basis of) ability to perform basic arithmetic, addition and subtraction, has been found as early as in five-month-old infants. In Wynn's (1992) seminal study, fivemonth old infants were shown basic arithmetical problems, by utilizing displays of dolls. In two separate experiments, infants were shown simple arithmetic. In alternating trials, the infants were shown either correct (i.e., $1+1=2 ; 2-1=1$ ) or incorrect (i.e., $1+1=1 ; 2-1=$ 2) results. Results revealed that the infants looked longer at the items containing errors (i.e., 1 $+1=1)$. Furthermore, as it could be argued that the incorrect items only contained the same amount as the first item, a third experiment utilized items where the incorrect answer was ascending (i.e., $1+1=2 ; 1+1=3$ ). The results again showed that the infants looked longer at the item containing the error (i.e., $1+1=3$ ). Wynn (1992) hypothesized that the results arose due to infants' basic innate arithmetic skills. However, studies attempting to replicate Wynn's (1992) experiment have been inconsistent, while a recent meta-analysis by Christodoulou, Lac, and Moore, (2017) of 12 studies also support Wynn's (1992) findings. However, in Bremner et al., (2017)'s replication of Wynn (1992), evidence from eye-tracking suggested that the five-month-old infants utilized their OTS' to track the objects. The 
increased looking time can therefore be understood as the infants' search for the last tag, inexplicably missing. Many researchers believe that this ability subsequently guides/supports arithmetic development.

Already prior to formal education, most children can perform basic verbal addition and subtraction tasks of small numbers (Aunio et al., 2014). In order to perform these rudimentary calculations, children develop various strategies known as counting strategies; sum, min, decomposition and fact retrieval (Geary \& Hoard, 2005; Siegler \& Shrager, 1984). Initially, children utilize external support such as manipulation of fingers or objects. By using external supports, the child can count either all fingers to come to their solution (count all), or they can count upwards from the smallest (count max) or largest (count min) number in the arithmetic problem. Children initially count out loud, using fingers or external supports to represent the numerosities. Thus, connecting non-symbolic numerosities (fingers) with symbolic representations (number words). Gradually, the fingers/external supports become internalized and the children can utilize aspects of working memory to keep the items in mind. With practice/experience and education, children's strategy use becomes adaptive. Most children will predominantly use the min-procedure, and later rely on memory/retrieval. However, the belief that adults primarily use retrieval has been questioned by studies showing that adults might actually utilize the same strategies that children use, but as the strategies are highly automatized they no longer require conscious effort nor the same level of attention as children require (see i.e., Uittenhove, Thevenot, \& Barrouillet, 2016).

\section{The hierarchical nature of math}

The relation between early and later mathematical knowledge is stronger than for other subjects (Duncan et al., 2007). One reason is that mathematical skill development is hierarchical, early knowledge/skill is needed in order to build later skills (Siegler \& Braithwaite, 2017). For example, having mastered the count sequence forms the foundation for being able to acquire basic addition, and addition fact knowledge in turn leads to an understanding of subtraction. Furthermore, understanding addition and subtraction forms a foundation for understanding multiplication. And later, understanding of multiplication helps the understanding of division and fractions. The notion of hierarchical acquisition of mathematics is also reflected in several international curricula, for example UK and US. They focus on counting and place values' importance in the early school years, and states their 
importance for progression into calculations, from single- to multi-digit tasks (McLean \& Rusconi, 2014).

Some hypothesize that the learning of arithmetical facts and the multiplication table could be done by rote, thus without connecting underlying non-symbolic number to the symbolic system though rote memorization. For example; Ashcraft, (1982) suggested that frequently solving identical problems through counting procedures leads to associations in long-term memory, along with computed answers. Thus, being able to retrieve arithmetic fact could be achieved by extensive training alone (Baroody, Bajwa, \& Eiland, 2009). Others, for example the integrative theory state that it is the inclusion of underlying (non-symbolic) representations in facts that make arithmetic meaningful and understandable, by enabling manipulation of quantities through mathematical operations (Siegler \& Braithwaite, 2017). Thus, predicting that facts and procedures will be learned faster and more meaningful with greater underlying representations. Furthermore, this aspect is also reflected in UK and US curricula where more focus is placed on conceptual understanding than mere procedural (McLean \& Rusconi, 2014). According to the integrative theory, the non-symbolic system's importance continues into advanced mathematical skills such as fractions and decimal use (Cirino, Tolar, Fuchs, \& Huston-Warren, 2016).

\section{What predicts future math achievement: Pathways to mathematics}

Although studies have investigated the development of the underlying non-symbolic systems, there are still only a few models that attempt to predict how early numeracy leads to later mathematical performance. Even fewer models take into account domain-general cognitive abilities and their role(s) in mathematics. One of them is the Pathways to mathematics model, inspired by the triple code-theory (Dehaene, 1992) previously described, and provides a framework to organize potential precursors (LeFevre et al., 2010). It states that three cognitive pathways (quantitative, linguistic, and spatial attention) contribute to non-formal and formal learning, and involves both non-symbolic and symbolic skills (LeFevre et al., 2010). The quantitative pathway is based on the assumption of a non-verbal capacity for number (i.e. the core number system). It forms the basis for and supports the (development of) exact, symbolic number system, acquired through language (linguistic pathway). As children learn the number words and Arabic digits through language, their meanings integrate and connect/map to the underlying quantitative system to form a verbal number code. The code also contains 
arithmetic facts and verbal counting (Dehaene, 1992). The spatial attention pathway is derived from studies linking visuo-spatial working memory to young children's mathematical performance.

To test the model, LeFevre et al., (2010) proposed two hypotheses. Firstly, all three pathways should contribute independently to early numeracy (LeFevre et al., 2010). However, the three pathways' importance varies, depending on stage in the child's development. The second hypothesis states that the three pathways vary in their unique and relative contribution to later mathematical performance, which depends on the demands and complexities of the task. The hypotheses were tested on four-to-six-year-old children (LeFevre et al., 2010), and results were mainly supportive. The first hypothesis, all pathways should contribute independently to early numeracy, was supported. The linguistic pathway predicted number naming but not nonlinguistic arithmetic, the quantitative pathway (subitizing) showed a reversed pattern, while the spatial attention predicted both tasks. The second hypothesis was also supported, as the pathways provided unique variability in all mathematical outcome measures, but with varying size (LeFevre et al., 2010).

Only two studies to my knowledge have directly tested the pathways model (Cirino, 2011; Sowinski et al., 2015), while Cirino et al., (2016) can be considered a possible extension of the original model and some authors, for example Vukovic and Lesaux, (2013a; 2013b) have focused on the linguistic pathway and its' predictability. However, the studies differ in respect to what measures are included in their cognitive pathways. The quantitative pathway was originally indexed utilizing subitizing (LeFevre et al., 2010), but has since been indexed by non-symbolic comparison, either measured utilizing dot comparison (Cirino, 2011; Cirino et al., 2016) and volume comparisons (Cirino, 2011), subitizing, enumeration and single-digit comparison (Sowinski et al., 2015). The linguistic pathway, originally tapped by receptive vocabulary and phonological processing, was replicated in Sowinski et al., (2015), whereas Cirino et al., (2016) included a vocabulary subtest and an auditory-verbal learning task, whereas Cirino (2011) utilized phonological awareness, RAN and a small addition task. The spatial attention pathway was originally tapped through spatial span task (Corsi-block), and the pathway was named due to possible confounds between spatial and working memory executive functioning (LeFevre et al., 2010). In subsequent studies, the spatial attention pathway has been measured utilizing spatial working memory measures (Cirino, 2011; Cirino et al., 2016), while Sowinski et al., (2015) expanded the spatial attention pathway to a 
working-memory pathway by utilizing additionally two measures, forward and backward digit span, besides the Corsi-block task. In addition to a spatial working memory pathway, Cirino et al., (2016) also included a spatial processing pathway, measured by mental rotation, to attempt to clarify the contributions from working memory and mental rotation.

The results have so far mostly been in support of the two hypotheses set forth by LeFevre et al., (2010). In one of the first studies testing the pathways model, Cirino's (2011) results revealed that the results were in accordance with the first hypothesis, as all pathways accounted for variation in digit comparison, counting, enumeration and symbolic knowledge. Sowinski et al., (2015) found that all expanded pathways predicted arithmetic fluency, whereas calculation was predicted by the quantitative and linguistic pathways. Thus, the results at first glance supported the first hypothesis. However, Sowinski et al., (2015)'s expanded quantitative pathway included symbolic aspects of number, digit comparison, and enumeration. As the original pathway model specifies that the quantitative pathway should be pre-verbal ("representing and operating on quantities"), Sowinski et al., (2015)'s results are difficult to interpret. Partial support for the first hypothesis was also found in Cirino et al., (2016), as the linguistic and spatial attention pathways predicted digit comparison, while the linguistic pathway predicted number line estimation and spatial attention pathway predicted arithmetic fact retrieval. In contrast to the first hypothesis, no other pathway predicted the basic arithmetic skills.

However, support for the second hypothesis, that all pathways should provide unique variability in all mathematical outcome measures, has varied. In Cirino (2011), none of the pathways predicted single-digit addition. Thus, not fulfilling the second hypothesis (Cirino, 2011). In contrast, the second hypothesis was supported in Cirino et al., (2016), as the quantitative and spatial processing pathways contributed directly to a standardized test, while the linguistic pathway contributed via proportional reasoning. Thus, the pathways contributed with varying size, depending on the complexities and demands of the task (Cirino et al., 2016). Sowinski et al., (2015) also found partial support for the second hypothesis, as all pathways related to backward counting and arithmetic fluency. However, not all pathways (only quantitative and linguistic) predicted calculation and number knowledge.

A possible explanation for the inconsistent results might be the included participants' ages. While LeFevre et al., (2010)'s original model was tested on children from four-to-six years 
old, studies since have utilized older children. Cirino (2011) assessed six-to-seven-year olds, Sowinski et al., (2015)'s participants were seven-to-eight year olds, while Cirino et al., (2016) focused on older (11-to-12-year old) children. The differing ages, predictors and outcome measures might explain the inconsistent results.

Research has consistently reported a link between aspects of linguistic skills, mathematical skill development and later arithmetic. Vukovic and Lesaux (2013b) attempted to clarify how different linguistic skills contribute to mathematical performance, by testing the Pathways model on third graders, but focused on the linguistic pathway to symbolic number processing and mathematical performance. The authors found that phonological skills directly influenced arithmetic skills, while more a general language measure (verbal analogies) contributed to a symbolic number processing measure. Phonological processing is believed to support the acquisition of number words, similar to the acquisition of language and literacy development (Gathercole, Alloway, Willis, \& Adams, 2006). Furthermore, addition and multiplication facts have been found to be stored in a linguistic format (Dehaene et al., 1999), and to solve arithmetic problems involves the conversion of terms and operator to speech-based code according to the Triple code theory (and the Pathways model) (Dehaene, 1992). Vukovic and Lesaux (2013b) hypothesized the contribution from phonological decoding represented the storing and retrieval of number from long-term memory. It is also assumed that the strength of the phonological representations enables easier retrieval. Several tasks tapping phonological processing have been linked to later mathematical achievement. Phonological awareness for example, assessed at preschool predicts later mathematical achievement (Alloway et al., 2005; Hecht, Torgesen, Wagner, \& Rashotte, 2001; Koponen, Aunola, Ahonen, \& Nurmi, 2007), later counting skills (Krajewski \& Schneider, 2009) and calculation skills (De Smedt, Taylor, Archibald, \& Ansari, 2010). Furthermore, phonological processing was found to be a unique determinant in arithmetic fact fluency, but no other measures of mathematical problem solving (Fuchs et al., 2005, 2006). Phonological working-memory is engaged when phonological name based codes are used to count, for example the count sequence (Geary, 1993). In summary, research has supported the claim that arithmetic facts are stored in verbal/linguistic format.

It has also been shown that rapid automatic naming (RAN) correlates with later calculation skills (Koponen et al., 2007; Koponen, Salmi, Eklund, \& Aro, 2013). However, RAN does not 
entail "pure" phonological processing, but might rather reflect rapid access to (verbal or semantic) long-term memory, to enable rapid processing to support speeded performance (Koponen et al., 2013). However, while RAN itself is a seemingly simple task, involves a complex amount of cognitive processes: attention, visual discrimination, integration of pattern information with orthographic representations, integration and activation of semantic and conceptual information and so forth (for review, see Norton \& Wolf, 2012). The precise relationship between RAN and reading is yet to be determined, and the same research question remains between RAN and mathematical skills.

Although these above-mentioned studies test the pathways model, other studies have measured different domain-general cognitive abilities' direct importance/contributions to mathematical development. In a recent review and meta-analysis, the capacity and efficiency of working memory (including central executive functions) was overall associated with mathematical skill development, but research has been inconsistent (for review see Friso-Van Den Bos, Van Der Ven, Kroesbergen, \& Van Luit, 2013). Furthermore, the meta-analysis revealed that different aspects of working memory might show stronger/weaker effect sizes depending on age of the participants, where some aspects of working memory are more important in early skill development whereas others are more important in later development, to support more advanced calculations. However, no single or all aspects of working memory have consistently predicted mathematical performance (Friso-Van Den Bos et al., 2013).

A possible explanation for the inconsistent results might be task impurity, where designed tasks also tap other abilities such as motor skills. Thereby causing measurement errors. Another possible explanation might be that different mathematical tasks might demand support from different domain-general abilities, which might explain conflicting research finds. For example, more advanced mathematical problems might demand more working memory support as they involve problem-solving, which in turn involves inhibition, to suppress wrong answers, inappropriate strategy use, conflicting or distracting irrelevant information from disturbing the problem-solving process. A more basic arithmetic skill like calculation, primarily demands fact retrieval from long-term memory. Furthermore, word problems demand reading ability, and thus phonological skills. 


\section{Developmental dyscalculia}

Despite adequate education and effort, cautiously estimated 5-6\% of the population worldwide suffer with severe mathematical difficulties. This pervasive learning disability has different labels in the literature, developmental dyscalculia, mathematical learning disorder, specific disorder of arithmetic skills (ICD-10) and so forth. The current thesis has chosen to utilize the term developmental dyscalculia (DD) henceforth. The term was dyscalculia was originally introduced to differentiate it from acquired mathematical difficulties, traumatic brain injury for example (Butterworth, 2005). In the latest edition of the Diagnostic and Statistical manual of mental disorders (DSM) fifth edition, Specific learning disorder is utilized as an umbrella diagnosis with a biological origin, where the psychologist specifies if the difficulties lie in reading and writing, or mastering number sense, number facts, the poor understanding of numbers and their magnitude, and the counting on fingers for single-digit numbers instead of using recall of arithmetic facts. Furthermore, the DSM-V notes the alternative term dyscalculia as referring to difficulties involving numerical processing, learning arithmetic facts and performing accurate or fluent calculations (American Psychiatric Association, 2013). Thus, there is a lack of consensus in both the scientific community and the diagnostic manuals for how the learning difficulty should be labeled.

One possible explanation for the differing names for the learning disorder might be that studies historically have varied in regard to what criteria were set up by the research community in diagnosis/assessment, and furthermore what measurements were used to assess (poor) performance and underlying skills. Two main approaches have dominated DD research. Historically, a discrepancy between IQ scores and math performance/achievement was the most prevalent definition, which was also historically used for dyslexia, to ensure that the diagnosis was not used to describe low general cognitive ability. However, this method has largely been discontinued. Mazzocco and Myers (2003) found in their longitudinal data that the discrepancy between IQ measures and performance did not differentiate between severity of deficits and the majority of the children in the data did not meet the discrepancy criteria. Furthermore, the children that did meet the criteria displayed variable characteristics and only represented a minority of the children with poor performance (Mazzocco \& Myers, 2003). The discontinuance of the discrepancy definition is also reflected in the change of the diagnostic manuals (DSM-IV vs. DSM-V criterion). 
The other, most common method used is to utilize a performance cut-off criterion, where children performing below a set percentile on for example a standardized math test or a combined measure of number processing and numerical cognition are characterized as DDgroup. The cut-off for classifying children as having/suffering from DD varies across studies, from 5-46:th percentile below performance. The most common cut-off are between the 1016:th percentile (De Smedt \& Gilmore, 2011; Geary, Hoard, Byrd-Craven, Nugent, \& Numtee, 2007; Hoard, Geary, Byrd-Craven, \& Nugent, 2008; Mazzocco, Feigenson, \& Halberda, 2011; Mejias, Grégoire, \& Noël, 2012; Mussolin, Mejias, \& Noël, 2010; Rousselle $\&$ Noël, 2007). Others use a combined measure of arithmetic measures (Piazza et al., 2010), or a combination of non-verbal logical reasoning and mental arithmetic (Castro, Reigosa, \& González, 2012). Another approach has been to utilize longitudinal data to ensure that children show developmental lag of 1.5-2 school years (Ashkenazi, Rubinsten, \& Henik, 2009; van der Sluis, de Jong, \& van der Leij, 2004), as research suggests that early, severe deficits are more likely to persist (Mazzocco \& Myers, 2003).

To investigate if the outcome of utilizing different cut-offs would differ, Murphy, Mazzocco, Hanich, \& Early, (2007) contrasted three groups' performances; below or at 11:th percentile, between 11-25:th percentile and those above the 25 :th percentile. The results revealed that the symptoms of DD varied with the cut-off criteria (Murphy et al., 2007). Further evidence for that DD symptoms might vary with the cut-off criteria used was provided by von Aster (2000). The author found a subclinical group that performed no lower than 1 SD (16:th percentile) below the normal achievers' performance on each measure, in contrast to the three DD groups that scored below 1.5 SD (9:th percentile) on more than one measure. This group, defined as poor/low performers made up $16.5 \%$ of the total sample, while the three other identified groups of DD children made up $4.7 \%$. Thus, the differing cut-off criterion might de facto describe qualitatively different children, with differing math and math-related skills that vary substantially. Conversely, some authors describe the above-mentioned concepts as being the same learning disability (Butterworth, 2010). These differences in cut-off values might also explain why the reported prevalence varies; between $1.3 \%$ and $10.3 \%$, with a mean estimate of 5-6\% (Devine, Soltész, Nobes, Goswami, \& Szucs, 2013). 


\section{The heterogeneous nature of DD}

The speculation that the above-mentioned learning disorder might refer to children with different underlying problems and differing manifestations of symptoms has sparked interest in the hypothesis of (functional) subtypes. As mathematical development is complex and hierarchical, with one skill required in order for learning of the next skill, the presented symptoms of DD are heterogeneous. DD children display a wide range of symptoms from subitizing, difficulty processing digits, spatial difficulties, time estimation and so forth (von Aster, 2000). Some children might also have the same underlying (neurological deficit), yet display different symptoms/mathematical deficits. Thus, children can show difficulties in different basic numerical skills for different reasons.

Three subtypes were originally suggested by Geary (1993) in order to explain result patterns; arithmetic fact retrieval, procedural and visuo-spatial subtypes. The arithmetic fact retrieval subtype, is defined by children who persistently fail/low frequency at retrieving arithmetic facts (i.eg., $1+2=3$ ). Being able to retrieve basic arithmetic facts is the foundation for subsequent mathematical skills, as retrieval frees cognitive resources to more demanding processes. Thus, facilitating problem-solving, mental and written calculations. The procedural subtype is characterized by a delay/inability to use counting strategies to solve addition problems, and rely to a greater extent on external support such as finger counting, commit more counting errors and adopt the min-strategy later (Geary et al., 2009). The children also show a delay in understanding underlying concepts. The third subtype is known as the visuospatial subtype, where the visuo-spatial representations of numerical information is impaired. The DD children's errors indicate a misinterpretation/misplaced spatially represented numerical information, such as place values (von Aster, 2000). The subtype also involves difficulties with sign confusion, number omission. According to Mazzocco \& Myers, (2003) the visuo-spatial subtype is the least understood of the three subtypes. Support for various subtypes and their respective result patterns has varied across several studies (Mazzocco \& Myers, 2003; von Aster, 2000).

Another interpretation has also been made to account for comorbidities associated with DD, such as dyslexia, ADHD. According several authors, the high numbers of comorbidities are inconsistent with the hypothesis of a homogenous genetic factor. Several authors suggest a division should be made between DD caused by deficits' cause (Kaufmann et al., 2013; 
Rubinsten \& Henik, 2009; von Aster \& Shalev, 2007). Pure or primary DD is caused by/restricted to specific basic numerical domains, caused by an early deficit in the core systems. Furthermore, the cause is likely due to a genetic predisposition. Secondary or mathematical learning difficulties, on the other hand is due to deficits in domain-general abilities, such as early speech and language delay, attentional deficits or deficits in executive functioning. These deficits impair the acquisition process of the symbolic number system. While the children with secondary DD might show similar impairments shown by children with pure DD, the secondary DD children's deficits are not caused by a deficit in the core number system. Most researchers posit that the majority of children suffering from DD are more likely to suffer from secondary DD, rather than pure DD (Kaufmann et al., 2013; Rubinsten \& Henik, 2009; von Aster \& Shalev, 2007).

\section{Core deficit}

In comparison to severe reading difficulties, dyslexia, research on DD has progressed slower. One of the major issues has been identifying/defining the underlying cause of the learning disorder. The two most prominent theories argue that DD is either due to a core deficit in the non-verbal number systems (ANS and/or OTS) detailed above, or an access deficit between the non-verbal number systems and the symbolic system.

According to the hypothesis of a deficit in the ANS and/or OTS, the root cause is an underlying deficit in one or both systems. As the core systems provide humans with an innate foundational understanding of number, provide the ability to represent sets and manipulate them, having a deficit in these systems impact the individual's ability to learn arithmetic and mathematical concepts. Specifically, the deficit in the ANS causes blurrier, less accurate underlying representations on the number line. This causes difficulties when making nonsymbolic comparisons or approximations, resulting in a lower acuity ( $w$-score). Additionally, subitizing speed, span and accuracy will be reduced as the OTS is impaired. Furthermore, the deficit also impacts symbolic processing. Deficits in (either or) the core systems in turn cause impairment in the developing symbolic system, as individuals are believed to map their symbolic representations on the non-symbolic (Feigenson et al., 2004). A blurrier, less accurate underlying representation when attempting to map for example " 15 " with 15 items or the number word, a slightly blurrier representation might lead to the digit (15) being matched to 14 items. Thus, leading to a slightly less accurate representation. This integration of the 
symbolic and the non-symbolic system is believed to in turn sharpen the underlying, nonsymbolic representations in turn (Pica et al., 2004). A deficit in the symbolic system also becomes evident through larger response times when determining which digit is numerically larger, digit comparison, and when performing approximations. Furthermore, larger distance effects and size effect are expected (Wilson \& Dehaene, 2007), as they are indicators of a less precise ANS (Gullick, Sprute, \& Temple, 2011).

Prior to 2007, most research materials contained predominantly symbolic tasks, digits and number words. The access deficit hypothesis was proposed by Rousselle and Noël (2007) following their seminal study. The authors contrasted DD children's symbolic and nonsymbolic performance, and found DD children performed with normal ratio effects and discriminated non-symbolic magnitudes with the same error rates as typical achievers, but where slower and less accurate when comparing digits. The DD children also showed only slightly reduced size and distance effects, indicating non-impaired non-symbolic representations, compared to the controls. Thus, the access deficit was suggested; that the root cause of DD is due to accessing the magnitude information from numerical symbols rather than number processing (Rousselle \& Noël, 2007). According to the access deficit hypothesis, DD children only show deficits on symbolic tasks, such as digit comparison.

Another alternative hypothesis is that the cause is due to a combination of domain general (cognitive abilities) deficiencies or several distinct delays. According to this hypothesis, the deficits displayed by children with DD are due to the cognitive systems that underlie mathematical skills, such as working-memory, speed of processing and executive functions (Geary et al., 2007). The role of non-verbal logical reasoning ability is also debated, as this ability constitutes the ability for acquiring skills during the life span and is not knowledge based (Bull et al., 2008). However, as research has predominately chosen to focus on the deficits in the ANS and/or OTS or a possible access deficit, the current thesis will not discuss this hypothesis further.

Studies attempting to identify the root cause of DD have shown inconsistent results. Some studies report un-impaired non-symbolic results with impaired symbolic results (e.g. Castro, Reigosa, \& González, 2012; De Smedt \& Gilmore, 2011; Iuculano, Tang, Hall, \& Butterworth, 2008), thus in support of the access deficit hypothesis. Conversely, others report various non-symbolic deficits (Price, Palmer, Battista, \& Ansari, 2012; Skagerlund \& Träff, 
2014; Willburger, Fussenegger, Moll, Wood, \& Landerl, 2008). Some studies (e.g. Landerl, Fussenegger, Moll, \& Willburger, 2009) also report impairment on both symbolic and nonsymbolic performance. Additionally, greater distance effects have been reported (Ashkenazi, Mark-Zigdon, \& Henik, 2009; Mussolin et al., 2010; Price, Holloway, Räsänen, Vesterinen, $\&$ Ansari, 2007), and larger size effects (Ashkenazi et al., 2009). Further support for the defective preverbal ANS and/or OTS hypothesis is evidence of reduced number acuity $(w)$ in DD children. Piazza et al.'s (2010) found both a reduced number acuity $(w)$ and a five year developmental lag, whereas Mazzocco et al., (2011) found significantly poorer $w$ and mappings of number words. However, the DD children in Chu, van Marle, and Geary (2013) study only showed impairment on ANS measured by accuracy (percentage), but not in $w$.

The evidence for deficits of the second core system, the OTS, have also been mixed. The system is frequently tapped through subitizing, where children with DD should hypothetically show a reduced range or slower performance. The original notion of a smaller/reduced subitizing range (being limited to two), came from Koontz and Berch (1996). The DD children in the authors' study appeared to be counting instead of subitizing above two, showing a steeper increase in both errors and reaction time. Since Koontz and Berch's (1996) study, some studies have replicated the result pattern (Andersson \& Östergren, 2012; Ashkenazi \& Henik, 2012; Ashkenazi, Mark-Zigdon, \& Henik, 2013; Moeller, Neuburger, Kaufmann, Landerl, \& Nuerk, 2009). Other studies have found DD children to perform subitizing slower, but no decrease in subitizing range (Desoete \& Grégoire, 2006; Schleifer \& Landerl, 2011; van der Sluis et al., 2004; Willburger et al., 2008). Some studies (Iuculano et al., 2008; Landerl et al., 2009) have however not found any significant differences between DD children and controls, which was also replicated with adolescents with DD (Ceulemans, Loeys, Hoppenbrouwers, \& Desoete, 2014).

As previously mentioned, there are no agreed upon standards or standardized measurements to tap number processing or numeric processing. While measures have (begun) including both symbolic and non-symbolic aspects since Rousselle \& Noël (2007), there is still issues concerning the tasks' comparability. When comparing ( 1 vs 3 ), and (X vs. XXX), one can argue that the non-symbolic task contains aspects such as cumulative area, and amount, since the Arabic digits take up identical space (area). While comparing ( 1 vs 3 ) and (10 vs 30 ) is the same ratio, the second numerosity is easier due to the distance effect. The difficulty in attempting to directly contrast symbolic and non-symbolic performance became evident in 
Rousselle and Noël's (2007) study. When the authors attempted to only alter format, but keeping the ratio's of $1 / 2$ vs $2 / 3$ (f.eg. 6 vs 28 ). However, this made the non-symbolic task too difficult, and many of the included children's performance was at chance level and $38 \%$ of DD and $31 \%$ of TA group were excluded (Rousselle \& Noël, 2007).

Developmental aspects of DD have also gained recent interest, specifically age. ANS acuity improves with age (Halberda \& Feigenson, 2008; Izard et al., 2009), and measures of $w$ reaches adult levels during pre-teen years (Halberda \& Feigenson, 2008). As previously mentioned, some studies have found DD children having reduced number acuity (w-scores) while other have not. However, according to Noël and Rousselle's (2011) review only older (above ten years) children show impairment on non-symbolic comparison task(s), whereas younger children do not. Conversely, children show deficits in symbolic comparison regardless of age DD. The authors hypothesize that the cause is a deficit in the acquisition of the first exact (symbolic) numbers through the OTS. As the exact number system and the underlying approximate symbolic are believed to integrate, it will in turn result in an increase in precision of the ANS in typical development. In the DD children however, the integration is distorted, impacting acuity (Noël \& Rousselle, 2011). 


\section{Computer-based interventions}

Entry-level math in elementary school is highly predictive of later arithmetic tests (Duncan et al., 2007). Children showing low numeracy in the pre-school class keep struggling throughout the pre-school class, and only catch up to the typical achievers' entry levels at the end of the year (Aunio et al., 2015). Furthermore, the children who struggle with math in the primary grades continue to struggle throughout schoolyears, and the predictability between early understanding of math and later achievement is stronger than other subjects (Laski \& Siegler, 2014). Thus, low numeracy at an early age can cause significant later deficits. Furthermore, to intervene is important to help children form an adequate foundation for later arithmetic learning.

There has been an increasing number of published studies evaluating computer-based interventions to improve numerical skills and learning in the recent years. There are many benefits to using computer-based interventions. They are relatively low-cost, can be used in various settings, provide individual training and progressive difficulty. However, current interventions practices vary in implementation, methods, intensity, goals and theoretical underpinnings. Interventions can aim to supplement other educational methods, thus acting preventive by increasing speed and efficacy of regular teaching. Other studies intervene post diagnosis (e.g., DD or developmental dyslexia) in order to reduce symptoms. Most current computer-based interventions however, aim to develop new ways of training numerical/mathematical competencies through theories of number processing (ANS, OTS or numerosity coding), assuming that training effects generalize to other domains of numerical cognition.

The majority of current computer-based interventions were primarily designed according to the ANS hypothesis. Two of the most scientifically evaluated are the Number Race (Wilson, Revkin, Cohen, Cohen, \& Dehaene, 2006) and Rescue Calcularis (Kucian et al., 2011). Both were designed based on the ANS, but focus on different aspects (of the hypothesis/theory). Rescue Calcularis is specifically designed to utilize a number line (0-100), metaphorically resembling the mental number line, and aims to improve the associations between number and space. The Number Race on the other hand, utilizes a game board reminiscent of traditional board games. Both computer-based programs however contain similar tasks, comparisons, counting and at the higher levels, arithmetic. The tasks included in the Number Race and Rescue Calcularis contains various formats of number processing, such as digits, non- 
symbolic quantities. The Number Race also specifically includes counting. The Number Race has been evaluated in several studies (Räsänen, Salminen, Wilson, Aunio, \& Dehaene, 2009; Sella, Tressoldi, Lucangeli, \& Zorzi, 2016; Wilson, Dehaene, Dubois, \& Fayol, 2009; Wilson et al., 2006), on several age groups and ability groups, including children with DD, children of low socio-economic status and most recently a non-selected group of children. Rescue Calcularis has been evaluated in two studies (Kucian et al., 2011; Käser et al., 2013), both studies included children with DD.

The only study that has reported specific training of the OTS, through subitizing, is Fischer, Phys, Köngeter, Biol, and Hartnegg, (2008). As many children with DD or low numeracy have deficits in subitizing and enumeration, the authors hypothesized that arithmetic could be improved through training subitizing and enumeration. The authors tested their hypotheses in two studies with children with low numeracy, but report them in a single paper. Both studies found that immediately post-intervention, the children became significantly faster at subitizing and enumerating. (Counterintuitively, the children's subitizing scores were only improved by $5 \%$.) Furthermore, the second study found a transfer effect (from subitizing and enumeration training) to an improved score on a standardized math test compared to a waitcontrol group of children of low numeracy. However, the study borderlines inclusion in the term computer-based intervention, since the study utilized a "small handheld instrument", containing a visual display and keyboard (Fischer et al., 2008).

Graphogame-Math is the only computer-based program to my knowledge that specifically focuses on exact numerosities and number symbols, thus similar to the theoretical assumptions of numerosity coding. Graphogame-Math has only been scientifically evaluated in Räsänen et al., (2009), and was utilized in comparison to the Number Race. As it was designed to function as a control software, the tasks are similar to the Number Race's (comparison, counting and at the higher levels, basic arithmetic).

There are also some studies of computer-based interventions that do not specifically describe their computer-based program's designs theoretical underpinnings, for example Praet and Desoete (2014). Rather, the authors wanted to investigate if training skills that predict/underlie future proficiency in arithmetic skills impacted future arithmetic skills, and chose to base their intervention around either counting or comparison skills. However, the comparison computer-program is conceptually similar to other ANS-based programs, as the program contains both symbolic aspects of number (Arabic digits and number words) and 
approximate numerosities (animals or dots). Furthermore, the connection between nonsymbolic and symbolic was (hypothetically) trained through comparisons between Arabic digits and number words, and dots and number words. A similar theoretical interpretation can be made about the authors' counting program, which contained exact number with an upper bound of six. Furthermore, these exact elements were connected to an Arabic digit or a number word by the child. Thus, conceptually overlapping with the theory of numerosity coding.

\section{Effect of interventions}

Overall, most previous computer-based interventions have been designed in accordance to the theory of the ANS. However, the above-mentioned studies, regardless of theoretical underpinnings, have only reported significant differences/improvements on a few of the included outcome measures, usually measured directly following intervention. An overview of the results of previously published studies and of Study III can be found in Table 1. Socalled transfer effects between training symbolic aspects of number (i.e., digits, number words) to the non-symbolic number system are very rare. Furthermore, it is difficult to interpret whether measured effects are transfer effects or an effect of training as it is difficult to determine from the above-mentioned studies how much time in respective study was spent on training arithmetic. It is not customary to report how much time is spent on respective level/task, especially for the computer-based interventions that involve different tasks, such as the Number Race. The only study that has reported how much time was spent on arithmetic was Wilson et al., (2009). The children reportedly only spent eight percent of their sessions on arithmetic, which the authors used to explain why there were no more significant effects of the Number Race. To date, there is no published study were children utilizing a computerbased program only train arithmetic.

It is also difficult to compare the effects of training as studies either do not utilize/report effect sizes, (Kucian et al., 2011; Wilson et al., 2009, 2006) and the studies that do, rarely use the same effect measures. Furthermore, the effects that are reported utilizing effect sizes report large differences in effect, for example Praet and Desoete (2014) found small significant effects in $\eta^{2}$ (0.06 - 0.09), whereas Käser et al., (2013) report medium-large effects measured by $r(0.38-0.52)$ and Sella et al., (2014) reported effects from small to very large effects as measured by corrected Hedge's $g$, (0.18 - 1.58). Sella et al., (2014)'s groups differed 
significantly when calculating the pre-test Hedge's $g$, which led to a need for inclusion of pretest value as covariate when calculating Hedge's gs on the post-measures.

The most reported effects are improvements on arithmetic, such as single-addition (Sella et al., 2016; Wilson et al., 2006), or subtraction (Käser et al., 2013) or combined measures (Kucian et al., 2011). Effects have also been found on single-digit comparison (Räsänen et al., 2009; Wilson et al., 2009) and an increase in precision of number line estimations (Kucian et al., 2011; Sella et al., 2016), and Kucian et al., (2011) have reported that their DD children made more linear placements on the number line task. No study to date have reported effects on the distance nor size effects of these measures, which would indicate a change in the precision of the underlying ANS' number line. Only three studies have reported (potential) effects on non-symbolic aspects of number. Sella et al., (2016) found a significant effect on a combined measure of non-symbolic and symbolic aspects of number, dot and digit comparison measure. It is thus unclear whether the significant difference arose from an improved symbolic or non-symbolic performance. Similarly, as mentioned above, Wilson et al., (2006) and Fischer et al., (2008) also found an increase in subitizing speed in their DD children. However, subitizing demands a verbal response and taps the OTS, which can be considered a domain-general aspect of number. Thus, the task is not a "pure" non-symbolic task unlike non-symbolic comparison and does not require a verbal response. None of the previously mentioned studies have found a significant difference on the non-symbolic comparison task.

Only three studies have utilized a delayed post-intervention measurement to study if the effects of intervention remain (Kucian et al., 2011; Praet \& Desoete, 2014; Räsänen et al., 2009). Three weeks post-intervention, Räsänen et al., (2009) found that the Graphogamemath group with DD still performed stronger than the other groups (Number Race, passive controls) on single-digit comparison, but no other significant effects emerged. Kucian et al., (2011) utilized a cross-over design where the effects of rest were investigated, where half of the DD children trained first and then rested and vice versa. Results showed that there was no difference on the significant effects on number line estimations and arithmetic, regardless if the post-measurement was immediate or five weeks post-intervention. Thus, the differences remained post-training. Another approach was used by Praet and Desoete (2014), where the authors investigated if computer-based interventions had an impact on later arithmetic development, by assessing the children on a standardized math test roughly six months postintervention. While not measuring the effects on the same tasks as previously utilized, both 
counting and comparison group showed stronger basic number knowledge (assessed through standardized test) than the control group. The counting group showed a significantly stronger performance on verbal arithmetic compared to controls (Praet \& Desoete, 2014).

There are several possible explanations for why significant effects are rare. One possible explanation is that children/participants with DD are more resistant to treatment, as DD is a developmental learning disorder with a biological origin. However, there does not appear to be any difference in amount of significant effects in studies including children with DD or non-selected children. Another possible explanation might be that studies vary with regard to the age of the subjects included. The most common option has been to include participants due to ability (e.g., DD), regardless of age, resulting in large age-spans. Fischer, Köngeter and Harnegg (2008) for example, included DD children aged 7-13, while others utilize a smaller/more narrow age range, such as Wilson et al., (2006a) included seven-to-nine-yearold children with DD. Similarly, Kucian et al., (2011) included children eight-to-ten-year olds. As DD has an estimated prevalence of 3-5\%, it is reasonable that these children are hard to recruit. Thus, causing a greater age-span. Another option has been to include children based on classroom setting, such as Praet and Desoete (2014) utilizing kindergartners (mean age of 5.6-years, standard deviation 4 months) while for example Sella et al., (2016)'s kindergartners were aged four-to-six-years old. However, the authors do not report any significant effect of age in their results sections.

The intervention intensity also varies, regardless of the program design. The total number of minutes spent using the various programs varies greatly, from 120-1200 minutes. Also, the time frame, over which the programs are used, vary greatly. The most intense/shortest interventions only last three weeks whereas the longest durations last for 12 weeks (See Table 1). There is no difference in amount of significant results due to intervention length; the longer interventions do not yield more significant results than the shorter interventions. However, it is not possible to judge if there are differences between the studies in the amount of time spent on arithmetic. It is plausible however that the studies including older children might have progressed faster to the higher levels where arithmetic is included, in for example Number Race and GraphoGame-Math. 


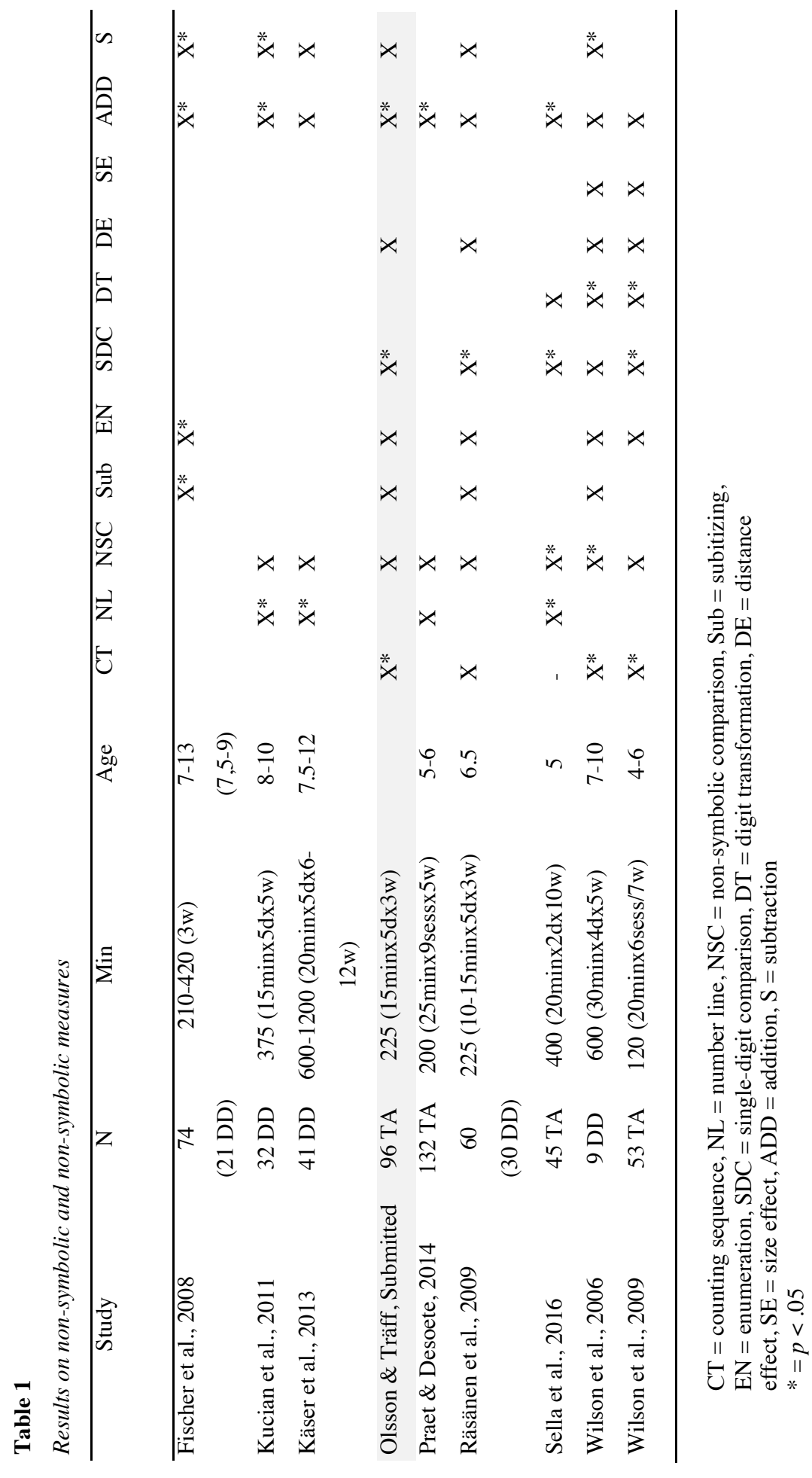




\section{Specific aims}

The overall aim of the thesis is to contribute to the description of what aspects of early number and symbolic number processing may lead to later (successful or unsuccessful) mathematical proficiency, and to study the effects of differently designed computer-based programs, designed in accordance with influential models of the core number system. In order to achieve the overall aim, more specific aims were used. One specific aim was to map the cognitive mechanisms underlying symbolic number processing and different arithmetic skills, and furthermore explore the conceptually accepted notion that arithmetical skills are hierarchical in nature, by investigating if more basic arithmetic skills contribute to more advanced arithmetic skills. Furthermore, by organizing domain-general cognitive abilities into a theoretical framework (Pathways model), I aim to investigate their influence/interaction with symbolic number processing, as they have been found to contribute to mathematical development/achievement. As previous studies have been performed on either younger or older children, a knowledge gap during late primary school years remains to be filled.

In order to achieve the aim of what aspects of number and symbolic number processing may lead to unsuccessful arithmetic proficiency, a more specific aim was to further the understanding of the underlying cause(s) for developmental dyscalculia, a pervasive learning disorder, by contrasting performance against two main hypotheses. Several hypothetical causes for developmental dyscalculia have been suggested, but no consensus has been reached. Previous research has implicated a contribution by domain-general cognitive abilities to mathematical achievement. In order to investigate the core deficit of developmental dyscalculia and to thus ensure the results were due to differences in number and numerical processing, domain-general cognitive abilities were controlled for by utilizing an individually matched control group.

The last specific aim was to investigate the effects of differently designed computer-based programs, designed in accordance with influential models of the core number system on preschool aged children. Furthermore, a future implication might be to provide more scientifically evaluated computer-based interventions for non-selected children in order to reduce the suffering caused by low mathematical proficiency, early in development. Thus, also potentially reducing the risk for lower mathematical proficiency in the future.

Furthermore, by combining the research finds from more or less mathematically proficient 
children might guide future studies of computer-based interventions for children with developmental dyscalculia.

This thesis consists of three studies. Study I and II are comprised of the same sample, whereas study III is a different sample.

\section{Empirical studies}

\section{Study I}

Background and aim. The process of becoming numerate is complex, and research has attempted to predict what aspects of early numeracy leads to later mathematical performance. Research has also found domain-general cognitive abilities contribute to arithmetic achievement. One of the few existing models that combines the contributions from early numeracy and general cognitive abilities, is the Pathways to mathematics model (LeFevre et al., 2010). The model states that three cognitive pathways (quantitative, linguistic and spatial attention) underlie early numeracy and later mathematical skill attainment. and their role(s) in mathematics. There are only a few studies attempting to replicate the original Pathway model (Cirino, 2011; Sowinski et al., 2015), and the results have been mixed. However, the combined results suggest that pathways' importance varies during development. In an attempt to further the understanding of what abilities underlie later arithmetic performance, study I expanded and modified the original pathways model, by including a spatial processing and a verbal working memory pathway in accordance with previous research. The overall aim of the study was to map the cognitive mechanisms underlying different arithmetic skills, and different hierarchical levels of arithmetic in third graders. Thus, children with relatively well-developed symbolic systems. In order to test the expanded Pathways model, LeFevre et al., (2010)'s two hypotheses were adopted and expanded. The first hypothesis was thus that the approximate quantitative, linguistic, spatial processing pathways should contribute provide independent contributions to symbolic processing, whereas the verbal working memory was not expected to contribute independently due to the included children's age. The second hypothesis was that the unique and relative contributions from the four pathways should vary, depending on the demands and complexity of the task. Due to the included children's age, the spatial processing pathway was only expected to contribute directly to arithmetic word problem solving. Lastly, in order to 
test the hierarchical levels of arithmetic, we hypothesized that the most advanced skill (arithmetic word problem-solving) should be supported by the more basic skills (symbolic processing, single-digit arithmetic, multi-digit calculation).

Method. A total of 269 third graders (aged 9-to-10 years old) were assessed on measures designed to tap abilities and skills based on the modified Pathway model. The data was analyzed using structural equation path analysis, in order to identify direct and indirect links among the measures.

Results and discussion. The quantitative and the linguistic pathway provided contributions to symbolic number processing, in accordance with the first hypothesis of the pathways model (LeFevre et al., 2010). The expanded and modified Pathways model is displayed in Figure 1. Thus, displaying the ANS ‘ importance in older children, as it seems to activate even for children with relatively well-developed symbolic systems. The linguistic pathways contribution was expected (see above discussion). However, the verbal working memory pathways did not contribute to digit comparison (symbolic number processing) in contrast to the first hypothesis, whereas the lack of contribution from the spatial processing pathway was expected. The results indicate the above-mentioned pathways have already played their part during the acquisition process. The second hypothesis, that the pathways' contributions should vary with the demands and complexities of the task, was supported as the linguistic pathway contributed to single-digit arithmetic and word problem solving. The approximate quantitative pathway also contributed, although indirectly, to single-digit arithmetic, and also provided a direct contribution (accuracy) to multi-digit calculation. Spatial processing and the verbal working memory pathways contributed to arithmetic word problem-solving, consistent with the predictions and previous research. Verbal working memory did not contribute to multi-digit calculation, in contrary to the second hypothesis. The results also supported the hypothesis of mathematical skills developing in a hierarchical fashion, as the less advanced arithmetic skills (i.e., single-digit arithmetic; multi-digit calculation) provided direct contributions to a more advanced skill (arithmetic word problem-solving), and single-digit arithmetic contributed directly to multi-digit calculation, and indirectly via multi-digit calculation to arithmetic word problem-solving. 


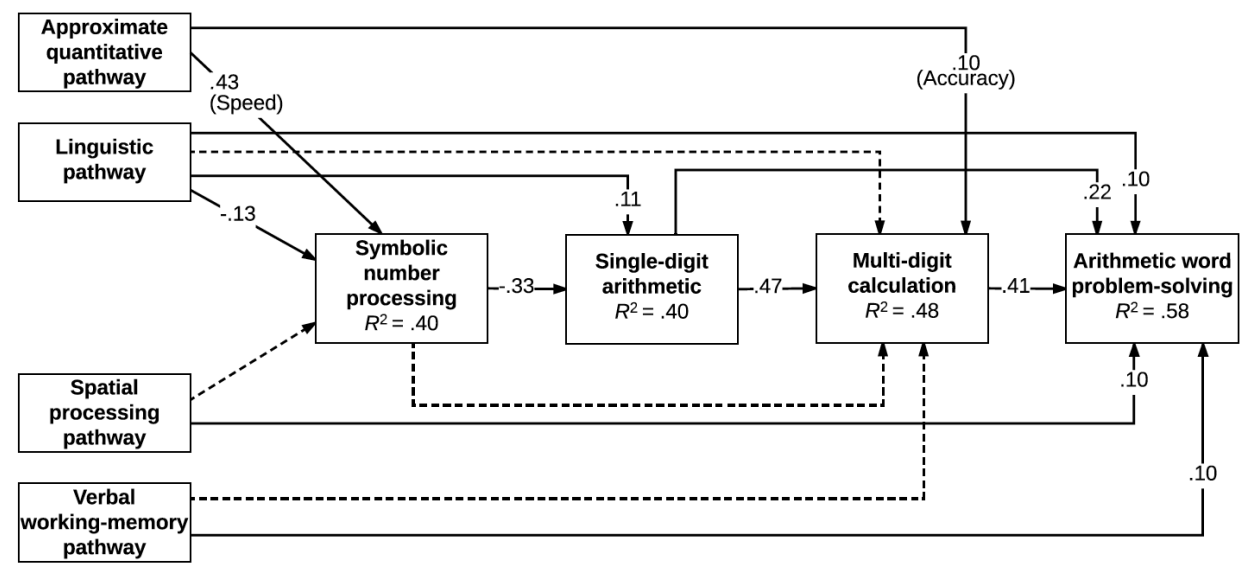

Figure 1. The expanded and modified Pathways model, tested by path analysis.

Significant $(p<.05)$ associations (standardized estimates) are displayed as full lines while non-significant associations are displayed as dotted lines.

\section{Study II}

Background and aim. As previously mentioned, developmental dyscalculia (DD) is a pervasive learning disorder with a biological origin (DSM-V). Despite having an estimated prevalence of 3-5 \%, there is no consensus on its' core deficit, despite several hypotheses. Several hypotheses have been proposed (Mussolin et al., 2010; Wilson \& Dehaene, 2007). One of the hypotheses is that DD is due to a specific (core) deficit in the preverbal number sense, theoretically supported by the two core systems; the ANS and/or OTS. The ANS handles large, approximate representations of number while the OTS handles small $(<4)$ sets. According to the hypothesis, children with DD suffer from blurrier, less precise representations of number, which in turn causes deficits when the exact, symbolic system is acquired. An alternative theory states that DD is caused by difficulties in accessing the underlying (intact) preverbal representations from the exact, symbolic system, such as digits and number words. While there is an alternative hypothesis that DD is caused by a combination of domain-general abilities (basic cognitive systems), the study attempted to control for this view by using various measures of general abilities. The aim of the study was to investigate DD's underlying deficit by contrasting third graders (10-year old) performance against predictions made by the two main hypotheses; the preverbal ANS and/or OTS and the access deficit hypothesis. More specifically, the preverbal ANS and/or OTS hypothesis predicts that DD children show deficits on both non-symbolic and symbolic number tasks, 
whereas the access deficit hypothesis predicts the DD children only show deficits on the symbolic tasks.

Method. From a non-selected sample of 292 children, 24 DD children's performance were contrasted against an individually matched control group consisting of 48 children. The control group was individually matched on age, non-verbal intelligence, gender, period of testing, and reading (word decoding). In order to identify the DD children, a mathematical screening was administered. The children with a combined score below/at 10:th percentile on the mathematical screening were classified as DD.

Results and discussion. The majority of the results were in support of the defective ANS and/or OTS hypothesis, as the DD children showed impairment on all symbolic tasks, except for a larger distance effect on double-digits compared to controls, and reaction times similar to controls on the enumeration (5-8 dots) measure. The DD group also showed a reduced subitizing range. Furthermore, the DD group showed significantly higher $w$-scores, lower accuracy scores but showed similar response times on the non-symbolic comparison task. (Thus, no trade-off between accuracy-speed.) However, the effect sizes of the symbolic tasks were greater, indicating greater impairment on the symbolic tasks. Results from a correlational analysis revealed several correlations among some measures, indicating some children were impaired on several measures. Table 2 from Study II shows the results of the individual detailed analysis. As the results revealed several impairments, an individual analysis was performed, and revealed that seven DD children showed impairment in line with the ANS/OTS hypothesis and seven in accordance with the access deficit. Notably, 13 of 24 DD children showed severe deficits on either or both digit comparison task. Furthermore, 21 of 24 children showed severe deficits $\left(<10^{\text {th }}\right.$ percentile) on at least one included measure. In summary, the results from study II suggest that although DD children showed impairment on non-symbolic tasks, they were most impaired on the symbolic tasks. Study II also suggests that perhaps the access deficit and the core deficit hypothesis could represent subgroups of DD. 
Table 2.

\begin{tabular}{|c|c|c|c|c|c|c|c|c|}
\hline DD & $w$ & A & S 1-4 & E 5-8 & SDC & DDC & $\mathrm{DE}$ & SE \\
\hline 1 & $\mathrm{X}$ & $X$ & - & - & - & - & - & - \\
\hline 2 & $\mathrm{X}$ & $X$ & $\mathrm{X}$ & - & - & - & - & - \\
\hline 3 & $x$ & $x$ & $x$ & - & - & - & - & - \\
\hline 4 & $x$ & $x$ & $x$ & $x$ & $x$ & $X$ & $X$ & $x$ \\
\hline 5 & $X$ & $x$ & - & $x$ & $X$ & $X$ & & $X$ \\
\hline 6 & $X$ & $X$ & $X$ & - & $x$ & $X$ & - & $X$ \\
\hline 7 & $X$ & $X$ & $X$ & $X$ & - & $X$ & - & - \\
\hline 8 & - & - & - & $X$ & $x$ & $X$ & - & $X$ \\
\hline 9 & - & - & $X$ & - & $X$ & $\mathrm{X}$ & - & $X$ \\
\hline 10 & - & - & $X$ & - & $x$ & $X$ & - & - \\
\hline 11 & - & - & $X$ & - & $X$ & $\mathrm{X}$ & $\mathrm{X}$ & - \\
\hline 12 & - & - & - & $x$ & $x$ & $X$ & - & - \\
\hline 13 & - & - & - & - & $X$ & $X$ & - & $X$ \\
\hline 14 & - & - & - & - & $X$ & - & - & - \\
\hline 15 & - & - & - & $X$ & - & $X$ & - & $X$ \\
\hline 16 & - & - & - & - & - & $X$ & - & - \\
\hline 17 & - & - & - & $X$ & - & - & $X$ & - \\
\hline 18 & - & - & $x$ & - & - & - & $X$ & - \\
\hline 19 & - & - & - & - & - & - & $X$ & \\
\hline 20 & - & - & $x$ & $X$ & - & - & - & - \\
\hline 21 & - & - & $X$ & - & - & - & $\mathrm{X}$ & - \\
\hline
\end{tabular}

DD: DD child, w: w-measure, A: accuracy on non-symbolic comparison task, S 1-4: subitizing 1-4 (slope), E 5-8: enumeration 5-8 (intercept), SDC: single-digit comparison, DDC: double-digit comparison, DE: distance effect (single-digit) and SE: size effect.

\section{Study III}

Background and aim. An increasing number of studies investigating the effects of computerbased training programs on arithmetic have been published over the past ten years. Early intervention is key, as research has shown that early deficits in/low numeracy is likely to remain and cause significant later deficits (e.g., Aunio et al., 2015; Laski \& Siegler, 2015). Most current computer-based programs were designed in order to intervene post-diagnosis of $\mathrm{DD}$, aiming to reduce or remedy symptoms. In order to target the root cause of DD and the associated deficits, these programs were designed in accordance with theories of number processing (e.g., ANS, OTS or numerosity coding) and assume effects will transfer to other domains of numerical cognition. Regardless of design of the computer-based programs, or sample (i.e., low numeracy, low socioeconomic status) most previous studies have obtained sparse (significant) results on symbolic aspects of number, such as digit-comparison and arithmetic. The non-symbolic aspects have remained uninfluenced (depending on how subitizing in interpreted). Furthermore, only two studies (scientifically) evaluating computerbased interventions on non-selected groups of pre-school class aged children have been published to this date (Praet \& Desoete, 2014; Sella et al., 2016).

It is unclear however how much time the children in the previous studies spent on arithmetic. Thus, the current study aimed to study the effects of arithmetic training through theoretically 
differently designs of computer programs, designed in accordance to hypotheses of number processing, on a non-selected sample of children and a passive control group. Three versions were designed; ANS, numerosity coding and conventional (drill) training. The main research question was to address if formal arithmetic is founded on an exact or approximate number system (i.e., numerosity coding vs. ANS) by comparing the effects of two versions of computer program. Another aim was to compare the effects of visual/external tools compared to conventional drill based training, used in traditional educational settings. While time and money is spent on developing programs, few studies compare visual/external tools' effect. Study III's final aim was to improve student's learning of basic arithmetic: addition and subtraction within the answering range of 1-20.

Method. A non-selected sample of 126 children participated in the study, across 8 schools, where the children used the program for $10 \mathrm{~min}$ per day, during 3 weeks. The children were randomly assigned to one of the four groups, that were equally represented across classrooms and schools. However, 30 of the children were excluded due to playing less than $13 / 15$ sessions. There were no significant differences between the groups on gender, domain general cognitive measures, measurements nor arithmetical measures pre-intervention.

Results and discussion. Analysis of the post-measurement revealed that the number line (ANS) group performed significantly faster than the exact numerosity (numerosity coding) group on single-digit comparison. The exact numerosity group performed stronger on arithmetic fluency, small addition, than both the number line and passive control group. The exact numerosity group also outperformed the controls on the arithmetic fluency, large addition measure. The conventional design group performed stronger than controls on the counting measure. There were no significant differences on the verbal arithmetic tasks, arithmetic fluency of subtraction, subitizing nor enumeration measures, no impact on the distance effect on the single-digit comparison, nor the non-symbolic comparison task $(w)$. The overall results replicate previous studies, as aspects of symbolic number processing were impacted whereas the measures hypothetically tapping the non-symbolic number system remained unaffected (Praet \& Desoete, 2014; Räsänen et al., 2009; Sella et al., 2016; Wilson et al., 2009). The number line group became significantly faster at digit comparison, replicating results in previous studies utilizing a design based on the theory of the ANS (Räsänen et al., 2009; Sella et al., 2016; Wilson et al., 2009). The exact numerosity group showed greater performance on the arithmetic fluency addition measure than the number line group and controls. The results partially replicate previous studies that have contrasted the designs of numerosity coding and the ANS (Praet \& Desoete, 2014; Räsänen et al., 2009). 


\section{General discussion}

The overall aim of the thesis is to contribute to the description of what aspects of early number and symbolic number processing may lead to later (successful or unsuccessful) mathematical proficiency, and to study the effects of differently designed computer-based programs, designed in accordance with influential models of the core number system. In order to achieve the overall aim, more specific aims were used. One specific aim was to map the cognitive mechanisms underlying symbolic number processing and different arithmetic skills, and furthermore explore the conceptually accepted notion that arithmetical skills are hierarchical in nature, by investigating if more basic arithmetic skills contribute to more advanced arithmetic skills. In order to achieve the aim of what aspects of number and symbolic number processing may lead to unsuccessful arithmetic proficiency, a more specific aim was to further the understanding of the underlying cause(s) for developmental dyscalculia, a pervasive learning disorder, by contrasting performance against two main hypotheses. The last specific aim was to investigate the effects of differently designed computer-based programs, designed in accordance with influential models of the core number system on pre-school aged children.

\section{The importance of the ANS}

The current thesis contributes to our understanding of the importance and continued importance of the non-symbolic representations/ANS' in arithmetic proficiency, both successful and unsuccessful, with several theoretically important findings. The current thesis extends previous evidence for the underlying non-symbolic representations' (ANS) continued importance in relatively educationally experienced children, with more or less developed symbolic systems. We show that the ANS (activation speed) contributed to symbolic number processing (digit comparison), which in turn contributed to a basic arithmetic skill (singledigit arithmetic) (study I). This important finding supports the theoretical notion that nonsymbolic representations support symbolic number processing. Theoretically, according to for example the integrative theory (i.e., Siegler \& Braithwaite, 2017), this finding indicates that the non-symbolic representations make digits and arithmetic more meaningful and understandable. Although the current findings do not indicate whether the symbolic system has mapped onto or integrated with the non-symbolic system, the present thesis presents evidence that there is a continued relationship even after the symbolic system has been acquired, and furthermore even when the children are educationally experienced. Thus, the 
symbolic system is not separate from the non-symbolic. It is also assumed that the quality of the non-symbolic representations affects access speed; a high-quality representation is easier to read, and thus faster to access. Thus, it seems reasonable that educationally experienced children continue to rely on fast access to the underlying non-symbolic representations.

The thesis also contributes with further important, novel evidence of ANS' (acuity) role in both successful and unsuccessful arithmetic performance. We found that ANS (acuity) contributed to a more advanced arithmetic skill (multi-digit calculation) in children with welldeveloped symbolic systems (study I). Our findings further supports the previously found correlations between ANS acuity and later arithmetic achievement (cf. Mussolin et al., 2012; Starr et al., 2013). The findings from the present thesis thus support the notion that highquality numerosity representations support symbolic number processing and advanced arithmetic skills (Halberda, Mazzocco, \& Feigenson, 2008), and that the relationship remains even for children with relatively well-developed symbolic systems (study I). This relationship might also help explain the exhibited difficulties in children with lower numeracy or DD difficulties. The combined findings from study I and II also suggest that ANS acuity is related to symbolic math achievement, as has been established by a recent meta-analysis by Chen and Li (2014). The authors found that ANS acuity ( $w$ ) correlated with symbolic math, even when controlling for moderators such as domain-general cognitive abilities.

The thesis also provides novel, important findings regarding the root cause of DD, and indicate that DD children's difficulties originate from a deficit in the ANS and/or OTS, leading to other severe deficits in arithmetic and symbolic number processing (study II). The findings taken together from study I show that the ANS contributes to both basic number processing tasks (digit comparison) and more advanced arithmetic tasks (single-digit arithmetic, multi-digit calculation), the deficits shown by DD children in study II (w-score, digit comparison, single-digit arithmetic, multi-digit calculation) are in line with the theory that a deficit in the ANS will in turn cause deficits in both non-symbolic and symbolic aspects of number processing (cf. Dehaene, 1992).

The present thesis makes a novel contribution to our knowledge of symbolic processing's (digit comparison) importance to arithmetic performance (Study I and II). Our findings revealed that symbolic number processing contributed, either directly or indirectly through another predictor, to both more basic arithmetic (single-digit) and more advanced arithmetic 
(multi-digit calculation) (Study I). The findings indicate that if symbolic processing is impaired, more advanced arithmetic will also show deficits. Indeed, our findings from Study II showed that DD children suffered the most severe impairments on both symbolic number processing tasks (single- and double-digit comparison), and performed at/below the $10:^{\text {th }}$ percentile on a mathematical screening battery. However, it remains unclear what the loci in DD children's arithmetic difficulties are: symbolic number processing per se, the retrieval of arithmetic facts or possibly an early disturbance in the developmental process of establishing the symbolic system, where the disturbance is cumulative over time. For future studies, it would be interesting to utilize self-reflection methods in children with DD solving arithmetic problems to discover the perceived symptoms, for example as children with dyslexia frequently report letters jumping.

There is an ongoing debate on ANS acuity's role in mathematical achievement. Most studies on the relationship between ANS acuity and mathematical achievement are correlational, where ANS acuity is measured earlier in time and the children's later achievement is measured later, Some studies report a correlation between ANS acuity and later arithmetic achievement (cf. Mussolin et al., 2012; Starr et al., 2013), whereas Purpura and Logan (2015) found a non-linear relationship, suggesting the ANS' importance changes with development. Fuchs and McNeil (2013) posit that the ANS' changing importance might reflect the mathematical concepts being learned at the time. As the mathematical operations/concepts are concrete at first, the children can directly utilize their underlying non-symbolic representations, causing a stronger association, whereas when mathematical concepts become increasingly more abstract the association decreases. Thus, explaining the result pattern. The theory is plausible for the children included in the present thesis (Study I and II), as the arithmetic tasks included in both Study I and II are more concrete than for example algebra, it is reasonable the children would utilize their underlying representations to solve the experimental tasks.

The thesis also contributes with scientific evidence for the notion of mathematical skills being hierarchical in nature. We found that an earlier acquired arithmetic skill (single-digit arithmetic) contributed to a more advanced skill (multi-digit arithmetic) (Study I). Our findings are also consistent with Cirino et al., (2016)'s findings. The assumption of math being hierarchically acquired has been acknowledged in several international math curricula, for example US and UK (McLean et al., 2014). The present thesis thus contributes to an 
increasing amount of scientific support for the educational view that arithmetic skill development is hierarchical, where previous skills underlie/form the foundation for later learned/acquired skills. To not properly acquire an early skill, thus has the potential to impact later skills (Study I). This reasoning is supported by our findings in study II. Although many children with DD show deficits in both the non-symbolic and symbolic system, the greatest deficits were shown on the symbolic, more advanced skills, thus later acquired skills. Thus, supporting the hierarchical reasoning of Study I. As the children included in Study II are third graders, with educational experience, it is unlikely the results were due to developmental delay.

The present thesis provides support for the hypothesis that non-symbolic representations forms the foundation for the symbolic system along with linguistic processes. Our findings demonstrated that linguistic skills contributed directly to symbolic number processing, basic and more advanced arithmetic along with non-symbolic processing (Study I). Our findings point out that language and non-symbolic representations are intertwined, even for children with relatively well-developed symbolic systems. As previously mentioned, it is still unclear what roles the core systems play in exact number's development. A recent study by Bremner et al., (2017) utilizing eye-tracking during children's performance of Wynn's (1992) classic experiment, implicated the OTS during the experiment which hypothetically taps rudimentary arithmetic in infants. The OTS has been hypothetically linked to subserve the acquisition of symbolic number, by matching individual tags to number words (e.g., Le Corre \& Carey, 2007). Similarly, the signature of the ANS is visible when children perform verbal estimations. Both the Triple-code theory and von Aster and Shalev's (2007) developmental model also predict that the mapping between non-symbolic and symbolic system is crucial for successful numerical and number processing. Although our results do not show the process of the systems' integration, they indicate the end result; that the non-symbolic system continues to influence symbolic processing and arithmetic. Furthermore, the findings add evidence that non-symbolic representations importance continues throughout development.

There has been speculation that the acquisition of the language-based exact, symbolic number system also affects ANS acuity, reciprocally. While it is known that ANS acuity sharpens over time, the cause of the sharpening is not yet clear. Our findings from Study III display how difficult it is to impact the ANS/non-symbolic representations through effortful training by computer-based programs. Only three previous studies have reported potential effects on 
non-symbolic aspects of number, and most are confounded. Either by the dependent measure needing a linguistic response (subitizing), a combined measure (non-symbolic and symbolic measures combined). To this date, the only studies that have reported effects on ANS precision have specifically trained non-symbolic comparison, which is also the task utilized to tap ANS precision. Thus, it remains unclear if the training causes true ANS acuity improvement or a pure training effect on the task itself. There is however evidence that nonsymbolic comparison (ANS) and non-symbolic numerical addition can impact arithmetic performance (Hyde et al., 2014; Wang et al., 2013). Evidence from most computer-based intervention studies however display that it is incredibly difficult to impact non-symbolic measures by performing symbolic tasks (see Table 1). Thus, while previous studies do indicate that manipulating or improving the non-symbolic representations do also improve the symbolic system, the vice versa reciprocity seems either more difficult to manipulate or previous research has not yet found appropriate methods or materials. Previous research do indicate that formal education do play a significant role (Nys et al., 2013; Piazza et al., 2013). However, it is not clear what aspects of formal education that impacts the ANS. Thus, the reciprocity between the non-symbolic and symbolic system is yet to be determined. However, almost all studies measuring ANS acuity (w) utilize the same or similar computer-based tasks. For future studies, it would be beneficial to attempt to tap the ANS with additional measures to ensure a stable measure.

\section{The language-based, symbolic number system}

The present thesis contributes with further evidence for linguistic processes' (language comprehension) contribution to symbolic number processing, and furthermore linguistic processes' contribution to both simpler arithmetic and more advanced mathematical tasks (Study I). Our findings indicate that linguistic processes along with non-symbolic representations indeed form the foundation for the acquired symbolic number system. Our findings regarding the linguistic pathway were thus in support of the first and second hypothesis of the pathways model (LeFevre et al., 2010). According to both the Pathways model and the Triple-code model, the linguistic pathway handles addition and multiplication facts, stored in verbal code/format and the transcoding between digits and number words (Dehaene, 1992; Lefevre et al., 2010). The claim has been supported in several studies (e.g., Dehaene et al., 1999). Phonological processing is believed to support the acquisition of 
number words, similar to language acquisition (Gathercole et al., 2006) and has been implicated in arithmetic (Vukovic \& Lesaux, 2013b).

As the linguistic pathway was the most important predictor in LeFevre et al., (2010) study, Vukovic and Lesaux (2013b) specifically tested specific linguistic skills' contributions in relation to the Pathways model and their contributions to arithmetic knowledge. The authors found that phonological skills influenced arithmetic skills whereas general verbal ability (verbal analogies) influenced symbolic number processing (number sequence). As we utilized a similar linguistic measure (language comprehension) and both arithmetic and symbolic number processing, our results regarding general verbal ability are similar to Vukovic and Lesaux' (2013b). Furthermore, Vukovic and Lesaux (2013a) suggest that general language is important for addition and subtraction, whereas language's role in multiplication and division remains to be determined. As we utilized arithmetic measures that mainly contained addition and subtraction, with increasing difficulty, our findings are in accordance with Vukovic and Lesaux' (2013a) predictions. Furthermore, humans from non-numerate cultures that lack a verbal count-sequence fail to perform exact calculations (Dehaene et al., 1999; Pica et al., 2004). Thus, language is crucial for exact symbolic calculations.

The present thesis also adds evidence for the hypothesis that language's importance continues throughout development and educational experience in symbolic number processing and mathematics (Study I). It has been hypothesized that more advanced arithmetic skills demand more linguistic contributions than basic arithmetic skills. Vukovic and Lesaux (2013a) found evidence that general language ability plays a vital role in more advanced mathematical concepts, besides in addition and subtraction. Thus, suggesting that languages role continues to be important besides retrieval of addition facts and transcoding between digits and number words. Our findings indeed show that the linguistic pathway contributed both directly and indirectly (through symbolic number processing, single-digit arithmetic and multi-digit calculation) to the most advanced arithmetic measure (arithmetic word problem- solving) included. Similarly, Cirino et al., (2016) found both direct and indirect contributions from the linguistic pathway to their most advanced mathematical measures, proportional reasoning and a state (achievement) test. In summary, the present thesis supports the hypothesis that linguistic abilities' importance continues, also for more advanced measures. 
To further attempt to clarify the potentially different roles of linguistic processes and verbal working memory, the present thesis included a verbal working memory pathway (Study I). Our findings provided further clarification that verbal working memory does not contribute to (basic) symbolic number processing nor multi-digit calculation in third graders. However, verbal working memory did contribute to arithmetic word problem-solving. Although verbal working memory has linked to arithmetic achievement in younger children (cf. Fuchs, Geary, Compton, Fuchs, Hamlett, \& Bryant, 2010; Fuchs, Geary, Compton, Fuchs, Hamlett, Seethaler, et al., 2010; Martin, Cirino, Sharp, \& Barnes, 2014), and to a certain degree in older children (cf. Sowinski et al., 2015), the present thesis thus suggests that verbal working memory is not key in symbolic number processing nor calculation for children with welldeveloped symbolic systems. Rather, it seems verbal working memory's role in third graders might contribution might be more in line with executive-working memory functioning rather than linguistic/phonological processing.

The present thesis also provides evidence for the spatial processing pathway's potentially changing role during development (Study I). Our findings were partially in contrast to the first hypothesis of the Pathways model, that all pathways should contribute independently to symbolic number processing, but were consistent with previous research (Cirino et al., 2016), as our spatial processing pathways did not contribute to symbolic number processing. Similar to the verbal working memory pathway, the spatial processing pathway contributed to arithmetic word problem-solving, but none of the other arithmetic tasks. While studies consistently report an association between spatial processing and mathematics, but the relation is unclear (Mix \& Cheng, 2012; Verdine, Golinkoff, Hirsh-Pasek, \& Newcombe, 2017). Our result pattern is most likely explained by age/educational experience. We included older children, at least three years older than LeFevre et al., (2010)'s children. Thus, despite having played a vital role during the acquisition process, spatial processing does not appear vital to nine-to-ten year olds. However, spatial processing did contribute to a more advanced arithmetic task, which supports the view that ill-defined, complex or novel mathematical problems are supported by spatial processes (Geary, 1993; Mix \& Cheng, 2012; van Garderen, 2006). There was however no contribution to the other two arithmetic tasks, similar to Cirino et al., (2016) and Szücs et al., (2014). However, we utilized mental rotation as the spatial processing task, it is possible that arithmetic is supported by another spatial processing skill. Visuo-spatial working memory has been found to be related to subitizing for example 
(Piazza et al., 2011). Another alternative interpretation is that mental rotation is not an important skill for older children, and is only important during the acquisition process of basic arithmetic.

\section{Developmental dyscalculia}

Another specific aim of the present thesis was to attempt to determine the root cause of DD, and the present thesis contributes with novel and important findings regarding the deficits of DD children as our findings indicate that DD children show deficits on both non-symbolic and symbolic number processing. Our findings were thus primarily in accordance with the defective ANS and/or OTS hypothesis (study II). Previous studies' results on the underlying cause of DD have been mixed, with some supporting the ANS and/or OTS hypothesis (e.g., Moeller et al., 2009; Price et al., 2012; Skagerlund \& Träff, 2014; Willburger et al., 2008), whereas others have been in support of the access deficit (e.g., (Castro et al., 2012; De Smedt \& Gilmore, 2011; Iuculano et al., 2008).

One of the core systems, the OTS, is most often tapped utilizing subitizing, the immediate recognition of numerosities up to four objects. Our findings show that DD children showed a reduced subitizing range compared to controls, similar to previous studies (cf. Ashkenazi et al., 2013; Koontz, 1996; Moeller et al., 2009) yet in contrast to other studies (Iuculano et al., 2008; Landerl, Bevan, \& Butterworth, 2004). The OTS is considered a domain general ability. However, we maintained close control for domain-general cognitive abilities by including an individually matched control group in study II, unlike other studies. It is thus unlikely that our findings reflect a deficit in domain-general cognitive abilities.

The findings from Study I indicate that domain-general cognitive abilities' role changes with development. The OTS' hypothetical developmental role is to aid in the establishment of the language based symbolic number system, by linking individual tags through one-onecorrespondence from numerosity to verbal, symbolic labels or vice versa (f.eg., LeCorre \& Carey, 2007). Furthermore, in a recent addition to the access deficit hypothesis, Noël and Rousselle (2011) hypothesize that an early deficit in the OTS might be the cause for children's difficulty when acquiring the earliest, exact number through language. This in turn leads to difficulties in progressing through the counting principles, as described above, and later on impacting the acuity of the ANS (Noël \& Rousselle, 2011). A similar account of the 
acquisition of exact, symbolic number is proposed by von Aster and Shalev (2007). However, we found no evidence that DD children were slower at subitizing 1-3 dots, but on subitizing 1-4 dots. Following ANOVAs for each numerosity (1-8), we found DD children were slower at subitizing/enumerating four and five dots respectively (study II), which is inconsistent with the access deficit hypothesis. Furthermore, our findings are in contrast to Noël and Rousselle (2011)'s claim that the primary disturbance in the OTS should not cause non-symbolic difficulties in children below ten years. As mentioned above, our DD children showed deficits on ANS acuity $(w)$ and seven of these children show severe impairment $(<10$ :th percentile). It is unlikely that these results arose as a mere consequence of a deficit in the OTS' of the DD children. Our results might however reflect a disturbance in the speed/access/flexibility of the DD children's count sequences, which might have led to the various symbolic number processing deficits. It remains possible that the DD children included in Study II previously had subitizing deficits in the 1-3 dot range, but that they have caught up to their peers, as the data included in study II is from a single measurement point.

While findings are in agreement with what qualifies as subitizing, an immediate and highly accurate recognition of numerosities where additional items cause an increase in reaction time and errors, there is no specific upper limit that defines the subitizing range. Some authors claim three, four, and some authors even claim their participants can subitize five dots. The only truly defining feature is reaction time and error increases. As research has shown that subitizing can be trained (cf. Fischer et al., 2008), one might wonder where the boundary for subitizing truly lies. Furthermore, to subitize involves providing a verbal response, which intrinsically is symbolic. Therefore, in the future it would be interesting if possible other measures of the OTS and subitizing will begin to develop, to remove the linguistic demands of the task.

The present thesis also highlights the difficulties in determining the underlying causes of low numeracy and DD (Study II). Study II included an inclusion criteria of $10:^{\text {th }}$ percentile, which is strict in comparison to other studies (cf. De Smedt \& Gilmore, 2011; Geary et al., 2007; Mazzocco et al., 2011). Furthermore, as previous research has indicated domain-general abilities in DD, and Study I highlights their contribution to symbolic number processing, the present thesis provides novel findings as Study II is the only study to date (to my knowledge) to include an individually matched control group on domain general cognitive abilities. Thus, ensuring focus on number and symbolic processing. Even after such rigorous screening, the 
result pattern following an individual analysis is evidence of DD's heterogeneous nature. As domain-general cognitive abilities were controlled for, the result pattern is not due to these differences.

The present thesis' control for domain general cognitive abilities is also interesting in relation to the debate on subgroups and the potential for pure and secondary DD, posited by several authors (cf. Kaufmann et al., 2013; Rubinsten \& Henik, 2009; von Aster \& Shalev, 2007). The definition of secondary DD entails that children should have deficits in language, attentional deficits and executive functioning. However, the children included in Study II should have neither impairment, due to the inclusion of such measures in the domain-general cognitive ability test battery. Thus, no child included in study II could suffer from secondary DD per von Aster and Shalev's (2007) definition. In contrast, children suffering from pure DD should show no impairment on their underlying core number systems (von Aster \& Shalev, 2007). Pure DD is also highly similar to the description of the access deficit hypothesis, previously described. Findings from Study II indicate that only 9/24 DD children in Study II showed no severe impairments on any non-symbolic task, in contrast to 13/24 DD children that did. Our findings thus highlight the difficulty in utilizing subgroups to attribute performance at group levels. A recent study by our research group highlights the difficulties in applying the primary/pure and secondary DD labels to actual children (Träff, Olsson, östergren, \& Skagerlund, 2017).

\section{Computer-based interventions}

Our findings from Study I show that arithmetic skills were hierarchical in nature in third graders, and suggest that interventions should aim to improve basic arithmetic and basic symbolic number processing in order to support arithmetic development. Study III was thus designed to primarily target basic arithmetic.

The present thesis contributes with novel and important findings regarding computer-based arithmetic training in the pre-school class, and our findings show that even brief, daily basic arithmetic training provided significant effects on several measures of symbolic number processing and addition (small and large) post-intervention (Study III). The present thesis also takes a novel approach to contributing to the debate on whether formal, symbolic mathematics is based on approximate or exact number system, by contrasting two versions' effects on 
arithmetic. Our findings show that exact representations in combination with digits provided a direct effect on addition (small and large), in contrast to approximate representations. Our results thus indicate that exact representations are more important for addition, whereas approximate representations in combinations with digits affect symbolic number processing. A possible explanation for our results might be that our exact numerosity version allowed children one-one-correspondence between magnitudes and digits, unlike the approximate version which did not entail sharp, delimited boundaries between the numerosities. Thus, the approximate version's visual tools did not help the children calculate, but rather possibly acted as a visual representation of the digits' physical size. Hence, the children performed a subtle digit comparison during the intervention, as the digits were possibly associated with size/length. Only one previous study has explicitly attempted to compare exact and approximate representations' impact on symbolic number processing and arithmetic (Räsänen et al., 2009), whereas Praet and Desoete (2014) can be interpreted as doing likewise. However, Räsänen et al., (2009) included DD children. Praet and Desoete's (2014) results are similar to ours, their exact numerosity group improved more on arithmetic skills compared to their approximate group. Räsänen et al.,'s (2009) exact numerosity group became faster at symbolic number processing. Praet and Desoete (2014)'s participants were non-selected preschoolers, just like Study III. In summary, our findings in combination with Praet and Desoete (2014)'s indicate that exact representations support early arithmetic learning more than approximate. It also seems reasonable as previously mentioned studies show that people from non-numerate cultures that lack exact, symbolic language fail at calculations but not approximations.

The present thesis also provides novel evidence that different theoretical designs yield different impacts on arithmetic and symbolic number processing (Study III). Unlike previous studies, we included a training program that did not contain any visual aids/support besides our exact and approximate representations versions. Our findings show that the conventional group, without visual aids/tools, showed stronger performance on the counting sequence measure (i.e., ordinality, cardinality, count sequence flexibility) compared to passive controls. Previous studies have found counting skills, and flexibility of the counting sequence predicts or supports future arithmetic learning (Aunola, Leskinen, Lerkkanen, \& Nurmi, 2004). Praet and Desoete (2014) found that their exact representation group that improved on counting also outperformed the other groups on a standardized math test one year post-intervention. As Study III only included an immediate post-measure, a delayed post-measure would be needed 
to determine Praet and Desoete's (2014) results would be replicated. Similar to other studies, our findings show the approximate representation version became faster at symbolic number processing (digit comparison) (cf. Wilson et al., 2009). Our findings from study I show that symbolic number processing contributes to single-digit arithmetic, which was specifically trained along with double-digit arithmetic in study III. It thus surprising that the approximate representations participants did not also improve on arithmetic. However, it remains possible that they will show improvement on arithmetic in the future. In summary, the findings from Study III show that the design and presence/lack of visual aids/tools do influence different aspects of symbolic processing.

Study III replicate previous research, of impacting symbolic number processing. None of our versions impacted our non-symbolic number processing measures, and thus replicate previous results (e.g., Käser et al., 2013; Praet \& Desoete, 2014; Räsänen et al., 2009; Wilson et al., 2009). There are some studies that have reported potential non-symbolic processing effects, but they are usually confounded with symbolic aspects, as mentioned above (cf. Fischer et al., 2008; Wilson et al., 2006). As previously discussed, there is debate regarding the reciprocity of the non-symbolic and symbolic systems. Study III adds to the debate by contributing evidence of arithmetic training does not influence the non-symbolic system, similarly as other studies performing comparisons, counting and estimations. The only training studies that seem to report a transfer effect, are from non-symbolic representation training leading to improvements on symbolic measures, such as arithmetic and symbolic number processing (cf. Fischer et al., 2008). In the future, it would be interesting to see more studies specifically target non-symbolic aspects of number, to attempt to discover what triggers the symbolic to non-symbolic system's reciprocity.

Most previous scientifically evaluated computer-based training programs have been designed to intervene post diagnosis of DD, and thus aim to improve on skills related to arithmetic or other domains of numerical cognition. The majority of the intervention studies have generated mixed results, but the majority of the effects are rather small. One might argue that DD children are more resistant to treatment. However, the studies that have included non-selected samples of children do not generate more effects than DD children. Although not explicitly tested in the current thesis, my hope is that study III will prevent future math difficulties for the participating children. Furthermore, by combining the research finds in study I, II and III, my hope is to conduct future studies implementing one or more versions of the developed 
computer-based training programs for children with DD based on the DD children's shown deficits.

\section{Conclusion}

The present thesis shows the importance of the pre-verbal non-symbolic system, even in educationally experienced children (Study I and II). Our findings support the notion that the symbolic system maps onto the non-symbolic (Study I), and furthermore provide further evidence that the root cause of DD is deficits in the ANS and the OTS (Study II). The DD children were also severely impaired on symbolic measures. If severe math difficulties and DD are indeed caused by a disconnection between the symbolic and the non-symbolic system, our findings (Study III) suggest that the connection is resistant to treatment. The present thesis also adds novel and important findings suggesting that formal arithmetic is indeed best supported by exact representations, not approximate (Study III). We also show that even breif, daily basic arithmetic training yield significant improvements on symbolic number processing in non-selected pre-school class children. Furthermore, the programs' different designs impacted different aspects of symbolic number processing. One version of the computerbased program might therefore be more advantageous for one child, whereas another child might benefit from another version, if the children have different deficits.

\section{Limitations}

Several limitations have to be considered for the present thesis. Some limitations are specific to each study included in the thesis, whereas some are overarching.

A general limitation when performing research with children in school settings is that the everyday life in schools always affect data collection. Despite careful planning, children become sick, some schools have limited locations to offer for data collection. In some cases, I have gathered data in less than ideal locations in contrast to other schools, who offered ideal circumstances. Furthermore, children's motivation and the relationship formed with the children during data collection might also impact the results. Sometimes, children are more motivated to participate due to the relationship and other times children are just not motivated to participate. In Study III, we attached a letter of consent written in order for the parents to read to the child before agreeing to participate in the study. It is however unclear whether this had an effect on the children's motivation and willingness to participate. It would be 
beneficial for future studies to also make note of whether the children's errors were due to lack of motivation and concentration or "pure" errors.

A related limitation is convincing school staff to participate in research studies. Although an invitation to participate in studies goes out to all schools in the district, most are accepted by the principals of the schools. The decision to participate is then not always anchored among the staff. In Study III, an intervention, adherence to the intervention was important in order to maintain fidelity. For future studies, it would be important to meet all participating staff and carefully explain all aspects of the study prior to data collection. If the importance of the research could be stressed and the possible implications explained, there is a possibility of increasing both interest for research and also increasing the odds for compliance to interventions.

A limitation in Study I and II is that all data was collected at a single-measurement point. To be able to fully describe and understand the hierarchy of arithmetic, for future studies it would be interesting to perform longitudinal studies to examine the hierarchy's development. Study I shows that the role of several domain-general cognitive abilities changes with development or educational experience, for example mental rotation. Thus, it would be of great interest to follow the developmental trajectory, and to discover for example how symbolic number processing is established and whether the contribution of certain abilities might vary in strength.

A significant limitation of study III, and most computer-based interventions is that although computer programs can be programmed intelligently and adaptively, no computer program can listen to a child explain why they do not comprehend an issue and provide an explanation that matches the child's confusion with large precision. While a computer program can be programmed to for example show a video sequence following the same error committed by a child more than x number of times, it can never listen and understand a child's problem relate it to that person's experiences and how that person understood it, like another human. In summary, can a computer program replace a teacher? My answer is no. I think computer programs can be best used for performing versus understanding. I think it is a much larger challenge to enable understanding than simple performance, as the difference in counting by rote and understanding cardinality represents. 


\section{Future implications}

Since the acquisition of the symbolic number system is slow, demanding and depend on other abilities that number processing, how do we take this into account in educational settings? No previously performed study has intervened for longer time frames than 12 weeks (i.e. 3 months), roughly half a school semester. For future studies, it would be interesting to study the effect of an integrated intervention where computer-based programs are utilized in close collaboration with the children's regular education. Will consistent support with arithmetic training provide greater results than a mere 3-week intervention? In the future, it would be interesting to perhaps administer the programs in different orders. Perhaps one program is more important during the early stages of arithmetic, whereas another is important during later stages.

As previously mentioned, it would be interesting to utilize mixed methods, utilizing selfreflection methods in combination with the regular quantitative measures. It would be valuable for clinicians to also have knowledge regarding the perceived symptoms encountered by DD children to discover difficulties early, to also provide our communities with a description of the perceived difficulties as dyslexia's "letters jumping".

The cost of being less mathematically competent is high, both for the individual and for our society. My hope is that the current thesis will contribute with providing a basis for testing the computer-based interventions utilized in Study III on children with mathematical difficulties or DD. The findings showed that designs, in accordance with influential models of the core number system, affected different aspects of symbolic number processing. As DD is a heterogeneous learning disorder, many children will have different deficits. Thus, one computer program might not be suitable for all DD children. For future intervention, as DD children might be more resistant to treatment, it would be interesting to match children's deficits to a specific version of computer program. Perhaps more individually tailored interventions might provide better effects than previous studies have generated?

Another hope of mine is to study the future effects of Study III, by following the included children. While only one post-measure has been become a manuscript, there is potential for later effects as suggested by previous research. My hope is that the present thesis can be used 
to continue the study of preventative interventions in order to prevent the suffering of lower mathematical proficiency in the future. 


\section{References}

Agrillo, C., Piffer, L., Bisazza, A., \& Butterworth, B. (2012). Evidence for two numerical systems that are similar in humans and guppies. PLoS ONE, 7(2), e31923. http://doi.org/10.1371/journal.pone.0031923

Alloway, T. P., Gathercole, S. E., Adams, A.-M., Willis, C., Eaglen, R., \& Lamont, E. (2005). Working memory and phonological awareness as predictors of progress towards early learning goals at school entry. British Journal of Developmental Psychology, 23(3), 417426. http://doi.org/10.1348/026151005X26804

American Psychiatric Association. (2013). Diagnostic and statistical manual of mental disorders: DSM-5. DSM- $V$.

Andersson, U., \& Östergren, R. (2012). Number magnitude processing and basic cognitive functions in children with mathematical learning disabilities. Learning and Individual Differences, 22, 701-714. http://doi.org/10.1016/j.lindif.2012.05.004

Ashcraft, M. H. (1982). The development of mental arithmetic: A chronometric approach. Developmental Review, 2(3), 213-236. http://doi.org/10.1016/0273-2297(82)90012-0

Ashkenazi, S., \& Henik, A. (2010). A disassociation between physical and mental number bisection in developmental dyscalculia. Neuropsychologia, 48, 2861-2868. http://doi.org/10.1016/j.neuropsychologia.2010.05.028

Ashkenazi, S., \& Henik, A. (2012). Does attentional training improve numerical processing in developmental dyscalculia? Neuropsychology. http://doi.org/10.1037/a0026209

Ashkenazi, S., Mark-Zigdon, N., \& Henik, A. (2009). Numerical distance effect in developmental dyscalculia. Cognitive Development, 24, 387-400. http://doi.org/10.1016/j.cogdev.2009.09.006

Ashkenazi, S., Mark-Zigdon, N., \& Henik, A. (2013). Do subitizing deficits in developmental dyscalculia involve pattern recognition weakness? Developmental Science, 16, 35-46. 
http://doi.org/10.1111/j.1467-7687.2012.01190.x

Ashkenazi, S., Rubinsten, O., \& Henik, A. (2009). Attention, automaticity, and developmental dyscalculia. Neuropsychology, 23, 535-540. http://doi.org/10.1037/a0015347

Aunio, P., Heiskari, P., Van Luit, J. E., \& Vuorio, J.-M. (2015). The development of early numeracy skills in kindergarten in low-, average- and high-performance groups. Journal of Early Childhood Research, 13(1), 3-16. http://doi.org/10.1177/1476718X14538722

Aunio, P., Korhonen, J., Bashash, L., \& Khoshbakht, F. (2014). Children's early numeracy in Finland and Iran. International Journal of Early Years Education, 22(4), 423-440. http://doi.org/10.1080/09669760.2014.988208

Aunola, K., Leskinen, E., Lerkkanen, M.-K., \& Nurmi, J.-E. (2004). Developmental Dynamics of Math Performance from Preschool to Grade 2. Journal of Educational Psychology, 96(4), 699-713. http://doi.org/10.1037/0022-0663.96.4.699

Baroody, A. J., Bajwa, N. P., \& Eiland, M. (2009). Why can’t johnny remember the basic facts? Developmental Disabilities Research Reviews, 15(1), 69-79. http://doi.org/10.1002/ddrr.45

Brannon, E. M. (2002). The development of ordinal numerical knowledge in infancy. Cognition, 83(3), 223-240. http://doi.org/10.1016/S0010-0277(02)00005-7

Brannon, E. M., Abbott, S., \& Lutz, D. J. (2004). Number bias for the discrimination of large visual sets in infancy. Cognition, 93(2), B59-68.

http://doi.org/10.1016/j.cognition.2004.01.004

Bremner, J. G., Slater, A. M., Hayes, R. A., Mason, U. C., Murphy, C., Spring, J., ... Johnson, S. P. (2017). Young infants' visual fixation patterns in addition and subtraction tasks support an object tracking account. Journal of Experimental Child Psychology, 162, 199-208. http://doi.org/10.1016/j.jecp.2017.05.007

Brody, L. E., \& Mills, C. J. (2005). Talent search research: What have we learned? High 
Ability Studies. http://doi.org/10.1080/13598130500115320

Butterworth, B. (2010). Foundational numerical capacities and the origins of dyscalculia. Trends in Cognitive Sciences, 14(12), 534-41. http://doi.org/10.1016/j.tics.2010.09.007

Cantlon, J. F., \& Brannon, E. M. (2007a). Basic math in monkeys and college students. PLoS Biology, 5(12), 2912-2919. http://doi.org/10.1371/journal.pbio.0050328

Cantlon, J. F., \& Brannon, E. M. (2007b). How much does number matter to a monkey (Macaca mulatta)? Journal of Experimental Psychology. Animal Behavior Processes, 33(1), 32-41. http://doi.org/10.1037/0097-7403.33.1.32

Castro, D., Reigosa, V., \& González, E. (2012). Symbolic and non-symbolic number magnitude processing in children with developmental dyscalculia. Spanish Journal of Psychology, 15(3), 952-966.

http://doi.org/http://dx.doi.org/10.5209/rev_SJOP.2012.v15.n3.39387 Copyright

Ceulemans, A., Loeys, T., Hoppenbrouwers, K., \& Desoete, A. (2014). To be or not to be: an informative non-symbolic numerical magnitude processing study about small versus large numbers in infants. Journal of Special Education and Rehabilitation, 15(1-2), 7590. Retrieved from http://oaji.net/articles/991-1404298247.pdf

Chen, Q., \& Li, J. (2014). Association between individual differences in non-symbolic number acuity and math performance: A meta-analysis. Acta Psychologica, 148, $163-$ 172. http://doi.org/10.1016/j.actpsy.2014.01.016

Christodoulou, J., Lac, A., \& Moore, D. S. (2017). Babies and math: A meta-analysis of infants' simple arithmetic competence. Developmental Psychology, 53(8), 1405-1417. http://doi.org/10.1037/dev0000330

Chu, F. W., van Marle, K., \& Geary, D. C. (2013). Quantitative deficits of preschool children at risk for mathematical learning disability. Frontiers in Psychology, 4, 195. http://doi.org/10.3389/fpsyg.2013.00195 
Cirino, P. T. (2011). The interrelationships of mathematical precursors in kindergarten. Journal of Experimental Child Psychology, 108(4), 713-733. http://doi.org/10.1016/j.jecp.2010.11.004

Cirino, P. T., Tolar, T. D., Fuchs, L. S., \& Huston-Warren, E. (2016). Cognitive and numerosity predictors of mathematical skills in middle school. Journal of Experimental Child Psychology, 145, 95-119. http://doi.org/10.1016/j.jecp.2015.12.010

Clayton, S., Gilmore, C., \& Inglis, M. (2015). Dot comparison stimuli are not all alike: The effect of different visual controls on ANS measurement. Acta Psychologica, 161, 177184. http://doi.org/10.1016/j.actpsy.2015.09.007

De Hevia, M. D., Girelli, L., Bricolo, E., \& Vallar, G. (2008). The representational space of numerical magnitude: Illusions of length. Quarterly Journal of Experimental Psychology, 61(10), 1496-1514. http://doi.org/10.1080/17470210701560674

De Hevia, M. D., Girelli, L., \& Vallar, G. (2006). Numbers and space: A cognitive illusion? Experimental Brain Research, 168, 254-264. http://doi.org/10.1007/s00221-005-0084-0

De Smedt, B., \& Gilmore, C. K. (2011). Defective number module or impaired access?

Numerical magnitude processing in first graders with mathematical difficulties. Journal of Experimental Child Psychology, 108, 278-292. http://doi.org/10.1016/j.jecp.2010.09.003

De Smedt, B., Taylor, J., Archibald, L., \& Ansari, D. (2010). How is phonological processing related to individual differences in children's arithmetic skills? Developmental Science, 13(3), 508-520. http://doi.org/10.1111/j.1467-7687.2009.00897.x

Dehaene, S. (1992). Varieties of numerical abilities. Cognition, 44(1-2), 1-42. http://doi.org/10.1016/0010-0277(92)90049-N

Dehaene, S. (2001). Précis of The Number Sense. Mind \& Language, 16(1), 16-36.

Dehaene, S., Bossini, S., \& Giraux, P. (1993). The mental representation of parity and number 
magnitude. Journal of Experimental Psychology: General, 122, 371-396.

http://doi.org/10.1037/0096-3445.122.3.371

Dehaene, S., Piazza, M., Pinel, P., \& Cohen, L. (2003). Three parietal circuits for number processing. Cognitive Neuropsychology, 20, 487-506.

http://doi.org/10.1080/02643290244000239

Dehaene, S., Spelke, E., Pinel, P., Stanescu, R., \& Tsivkin, S. (1999). Sources of mathematical thinking: behavioral and brain-imaging evidence. Science (New York, N.Y.), 284, 970-974. http://doi.org/10.1126/science.284.5416.970

Desoete, A., \& Grégoire, J. (2006). Numerical competence in young children and in children with mathematics learning disabilities. Learning and Individual Differences, 16, 351367. http://doi.org/10.1016/j.lindif.2006.12.006

Devine, A., Soltész, F., Nobes, A., Goswami, U., \& Szucs, D. (2013). Gender differences in developmental dyscalculia depend on diagnostic criteria. Learning and Instruction, 27, 31-39. http://doi.org/10.1016/j.learninstruc.2013.02.004

Dougherty, C. (2003). Numeracy, literacy and earnings: Evidence from the National Longitudinal Survey of Youth. Economics of Education Review, 22(5), 511-521. http://doi.org/10.1016/S0272-7757(03)00040-2

Duncan, G. J., Dowsett, C. J., Claessens, A., Magnuson, K., Huston, A. C., Klebanov, P., ... Japel, C. (2007). School readiness and later achievement. Developmental Psychology, 43(6), 1428-1446. http://doi.org/10.1037/0012-1649.43.6.1428; 10.1037/00121649.43.6.1428.supp (Supplemental)

Feigenson, L., Carey, S., \& Spelke, E. (2002). Infants' Discrimination of Number vs. Continuous Extent. Cognitive Psychology, 44(1), 33-66. http://doi.org/10.1006/cogp.2001.0760

Feigenson, L., Dehaene, S., \& Spelke, E. (2004). Core systems of number. Trends in 
Cognitive Sciences, 8(7), 307-314. http://doi.org/10.1016/j.tics.2004.05.002

Fischer, B., Phys, D., Köngeter, A., Biol, D., \& Hartnegg, K. (2008). Effects of Daily Practice on Subitizing, Visual Counting, and Basic Arithmetic Skills. Optometry \& Vision Development, 39(1), 30-34.

Friso-Van Den Bos, I., Van Der Ven, S. H. G., Kroesbergen, E. H., \& Van Luit, J. E. H. (2013). Working memory and mathematics in primary school children: A meta-analysis. Educational Research Review, 10, 29-44. http://doi.org/10.1016/j.edurev.2013.05.003

Fuchs, L. S., Compton, D. L., Fuchs, D., Paulsen, K., Bryant, J. D., \& Hamlett, C. L. (2005). The Prevention, Identification, and Cognitive Determinants of Math Difficulty. Journal of Educational Psychology, 97(3), 493-513. http://doi.org/10.1037/0022-0663.97.3.493

Fuchs, L. S., Fuchs, D., Compton, D. L., Powell, S. R., Seethaler, P. M., Capizzi, A. M., ... Fletcher, J. M. (2006). The cognitive correlates of third-grade skill in arithmetic, algorithmic computation, and arithmetic word problems. Journal of Educational Psychology, 98(1), 29-43. http://doi.org/10.1037/0022-0663.98.1.29

Fuchs, L. S., Geary, D. C., Compton, D. L., Fuchs, D., Hamlett, C. L., \& Bryant, J. D. (2010). The contributions of numerosity and domain-general abilities to school readiness. Child Development, 81(5), 1520-1533. http://doi.org/10.1111/j.1467-8624.2010.01489.x

Fuchs, L. S., Geary, D. C., Compton, D. L., Fuchs, D., Hamlett, C. L., Seethaler, P. M., ... Schatschneider, C. (2010). Do different types of school mathematics development depend on different constellations of numerical versus general cognitive abilities? Developmental Psychology, 46(6), 1731-1746. http://doi.org/10.1037/a0020662

Gathercole, S. E., Alloway, T. P., Willis, C., \& Adams, A.-M. (2006). Working memory in children with reading disabilities. Journal of Experimental Child Psychology, 93(3), 265-281. http://doi.org/10.1016/j.jecp.2005.08.003

Geary, D. C. (1993). Mathematical disabilities: Cognitive, neuropsychological, and genetic 
components. Psychological Bulletin, 114(2), 345-362. http://doi.org/10.1037//00332909.114.2.345

Geary, D. C., Bailey, D. H., Littlefield, A., Wood, P., Hoard, M., \& Nugent, L. (2009). Firstgrade predictors of mathematical learning disability: A latent class trajectory analysis. Cognitive Development, 24(4), 411-429. http://doi.org/10.1016/j.cogdev.2009.10.001

Geary, D. C., \& Hoard, M. K. (2005). Learning disabilities in arithmetic and mathematics: Theoretical and empirical perspectives. Handbook of Mathematical Cognition, 253-267.

Geary, D. C., Hoard, M. K., Byrd-Craven, J., Nugent, L., \& Numtee, C. (2007). Cognitive mechanisms underlying achievement deficits in children with mathematical learning disability. Child Development, 78(4), 1343-59. http://doi.org/10.1111/j.14678624.2007.01069.x

Gelman, R., \& Gallistel, C. R. (1978). The Child's Understanding of Number. Cambridge, MA: Harvard University Press.

Gerardi, K., Goette, L., \& Meier, S. (2013). Numerical ability predicts mortgage default. Proceedings of the National Academy of Sciences, 110(28), 11267-11271. http://doi.org/10.1073/pnas.1220568110

Gullick, M. M., Sprute, L. a., \& Temple, E. (2011). Individual differences in working memory, nonverbal IQ, and mathematics achievement and brain mechanisms associated with symbolic and nonsymbolic number processing. Learning and Individual Differences, 21(6), 644-654. http://doi.org/10.1016/j.lindif.2010.10.003

Halberda, J., \& Feigenson, L. (2008). Developmental change in the acuity of the "Number Sense": The Approximate Number System in 3-, 4-, 5-, and 6-year-olds and adults. Developmental Psychology, 44, 1457-1465. http://doi.org/10.1037/a0012682

Halberda, J., Mazzocco, M. M. M., \& Feigenson, L. (2008). Individual differences in nonverbal number acuity correlate with maths achievement. Nature, 455, 665-668. 
http://doi.org/10.1038/nature07246

Hecht, S. A., Torgesen, J. K., Wagner, R. K., \& Rashotte, C. A. (2001). The Relations between Phonological Processing Abilities and Emerging Individual Differences in Mathematical Computation Skills: A Longitudinal Study from Second to Fifth Grades. Journal of Experimental Child Psychology, 79(2), 192-227. http://doi.org/10.1006/jecp.2000.2586

Hoard, M. K., Geary, D. C., Byrd-Craven, J., \& Nugent, L. (2008). Mathematical cognition in intellectually precocious first graders. Developmental Neuropsychology, 33, 251-276. http://doi.org/10.1080/87565640801982338

Hogan, T. P., Catts, H. W., \& Little, T. D. (2005). The Relationship Between Phonological Awareness and Reading: Implications for the Assessment of Phonological Awareness. Language, Speech, and Hearning Services in Schools, 36(4), 285-293.

Hyde, D. C., Khanum, S., \& Spelke, E. S. (2014). Brief non-symbolic, approximate number practice enhances subsequent exact symbolic arithmetic in children. Cognition, 131(1), 92-107. http://doi.org/10.1016/j.cognition.2013.12.007

Inglis, M., \& Gilmore, C. (2014). Indexing the approximate number system. Acta Psychologica, 145, 147-155. http://doi.org/10.1016/j.actpsy.2013.11.009

Iuculano, T., Tang, J., Hall, C. W. B., \& Butterworth, B. (2008). Core information processing deficits in developmental dyscalculia and low numeracy. Developmental Science, 11, 669-680. http://doi.org/10.1111/j.1467-7687.2008.00716.x

Izard, V., Sann, C., Spelke, E. S., \& Streri, A. (2009). Newborn infants perceive abstract numbers. Proceedings of the National Academy of Sciences of the United States of America, 106, 10382-10385. http://doi.org/10.1073/pnas.0812142106

Kamawar, D., LeFevre, J. A., Bisanz, J., Fast, L., Skwarchuk, S. L., Smith-Chant, B., \& Penner-Wilger, M. (2010). Knowledge of counting principles: How relevant is order 
irrelevance? Journal of Experimental Child Psychology, 105(1-2), 138-145.

http://doi.org/10.1016/j.jecp.2009.08.004

Kaufmann, L., Mazzocco, M. M., Dowker, A., von Aster, M., Göbel, S. M., Grabner, R. H., ... Nuerk, H.-C. (2013). Dyscalculia from a developmental and differential perspective. Frontiers in Psychology, 4, 516. http://doi.org/10.3389/fpsyg.2013.00516

Koontz, K. L. (1996). Identifying Simple Numerical Stimuli: Processing Inefficiencies Exhibited by Arithmetic Learning Disabled Children. Mathematical Cognition. http://doi.org/10.1080/135467996387525

Koontz, K. L., \& Berch, D. (1996). Identifying Simple Numerical Stimuli: Processing Inefficiencies Exhibited by Arithmetic Learning Disabled Children. Mathematical Cognition. http://doi.org/10.1080/135467996387525

Koponen, T., Aunola, K., Ahonen, T., \& Nurmi, J. E. (2007). Cognitive predictors of singledigit and procedural calculation skills and their covariation with reading skill. Journal of Experimental Child Psychology, 97(3), 220-241.

http://doi.org/10.1016/j.jecp.2007.03.001

Koponen, T., Salmi, P., Eklund, K., \& Aro, T. (2013). Counting and RAN: Predictors of arithmetic calculation and reading fluency. Journal of Educational Psychology, 105(1), 162-175. http://doi.org/10.1037/a0029285

Krajewski, K., \& Schneider, W. (2009). Exploring the impact of phonological awareness, visual-spatial working memory, and preschool quantity-number competencies on mathematics achievement in elementary school: Findings from a 3-year longitudinal study. Journal of Experimental Child Psychology, 103(4), 516-531. http://doi.org/10.1016/j.jecp.2009.03.009

Kucian, K., Grond, U., Rotzer, S., Henzi, B., Schönmann, C., Plangger, F., ... von Aster, M. (2011). Mental number line training in children with developmental dyscalculia. 
NeuroImage, 57(3), 782-795. http://doi.org/10.1016/j.neuroimage.2011.01.070

Käser, T., Baschera, G.-M., Kohn, J., Kucian, K., Richtmann, V., Grond, U., ... von Aster, M. (2013). Design and evaluation of the computer-based training program Calcularis for enhancing numerical cognition. Frontiers in Psychology, 4(August), 489. http://doi.org/10.3389/fpsyg.2013.00489

Landerl, K., Bevan, A., \& Butterworth, B. (2004). Developmental dyscalculia and basic numerical capacities: A study of 8-9-year-old students. Cognition, 93, 99-125. http://doi.org/10.1016/j.cognition.2003.11.004

Landerl, K., Fussenegger, B., Moll, K., \& Willburger, E. (2009). Dyslexia and dyscalculia: Two learning disorders with different cognitive profiles. Journal of Experimental Child Psychology, 103, 309-324. http://doi.org/10.1016/j.jecp.2009.03.006

Laski, E. V, \& Siegler, R. S. (2014). Learning from number board games: you learn what you encode. Developmental Psychology, 50(3), 853-64. http://doi.org/10.1037/a0034321

Le Corre, M., \& Carey, S. (2007). One, two, three, four, nothing more: An investigation of the conceptual sources of the verbal counting principles. Cognition, 105(2), 395-438. http://doi.org/10.1016/j.cognition.2006.10.005

LeFevre, J. A., Fast, L., Skwarchuk, S. L., Smith-Chant, B. L., Bisanz, J., Kamawar, D., \& Penner-Wilger, M. (2010). Pathways to Mathematics: Longitudinal Predictors of Performance. Child Development, 81(6), 1753-1767. http://doi.org/10.1111/j.14678624.2010.01508.x

Lipton, J. S., \& Spelke, E. S. (2003). Origins of Number Sense: Large-number discrimination in Human Infants. Psychological Science, 14(5), 396-401.

Martin, R. B., Cirino, P. T., Sharp, C., \& Barnes, M. (2014). Number and counting skills in kindergarten as predictors of grade 1 mathematical skills. Learning and Individual Differences, 34, 12-23. http://doi.org/10.1016/j.lindif.2014.05.006 
Mazzocco, M. M. M., Feigenson, L., \& Halberda, J. (2011). Impaired acuity of the approximate number system underlies mathematical learning disability (dyscalculia). Child Development, 82, 1224-1237. http://doi.org/10.1111/j.1467-8624.2011.01608.x Mazzocco, M. M. M., \& Myers, G. F. (2003). Complexities in Identifying and Defining Mathematics Learning Disability in the Primary School-Age Years. Annals of Dyslexia, 53(1), 218-253. http://doi.org/10.1007/s11881-003-0011-7

McCrink, K., \& Wynn, K. (2007). Ratio abstraction by 6-month- old infants. Psychological Science, 18(8), 740-745. http://doi.org/10.1111/j.1467-9280.2007.01969.x

McLean, J. F., \& Rusconi, E. (2014). Mathematical difficulties as decoupling of expectation and developmental trajectories. Frontiers in Human Neuroscience, 8(February), 44. http://doi.org/10.3389/fnhum.2014.00044

Mejias, S., Grégoire, J., \& Noël, M. P. (2012). Numerical estimation in adults with and without developmental dyscalculia. Learning and Individual Differences, 22(1), 164170. http://doi.org/10.1016/j.lindif.2011.09.013

Mix, K. S., \& Cheng, Y. L. (2012). The Relation Between Space and Math. Developmental and Educational Implications. Advances in Child Development and Behavior, 42, $197-$ 243. http://doi.org/10.1016/B978-0-12-394388-0.00006-X

Moeller, K., Neuburger, S., Kaufmann, L., Landerl, K., \& Nuerk, H. C. (2009). Basic number processing deficits in developmental dyscalculia: Evidence from eye tracking. Cognitive Development, 24(4), 371-386. http://doi.org/10.1016/j.cogdev.2009.09.007

Moyer, R. S., \& Landauer, T. K. (1967). Time required for Judgements of Numerical Inequality. Nature, 215(5109), 1519-1520. http://doi.org/10.1038/2151519a0

Murphy, M. M., Mazzocco, M. M. M., Hanich, L. B., \& Early, M. (2007). Cognitive characteristics of children with mathematics learning disability (MLD) vary as a function of the cutoff criterion used to define MLD. Retrieved July 2, 2014, from 
http://msdp.kennedykrieger.org/pdf/35.pdf

Mussolin, C., Mejias, S., \& Noël, M. P. (2010). Symbolic and nonsymbolic number comparison in children with and without dyscalculia. Cognition, 115, 10-25. http://doi.org/10.1016/j.cognition.2009.10.006

Mussolin, C., Nys, J., Leybaert, J., \& Content, A. (2012). Relationships between approximate number system acuity and early symbolic number abilities. Trends in Neuroscience and Education, 1(1), 21-31. http://doi.org/10.1016/j.tine.2012.09.003

Negen, J., \& Sarnecka, B. W. (2015). Is there really a link between exact-number knowledge and approximate number system acuity in young children? British Journal of Developmental Psychology, 33(1), 92-105. http://doi.org/10.1111/bjdp.12071

Noël, M.-P., \& Rousselle, L. (2011). Developmental Changes in the Profiles of Dyscalculia: An Explanation Based on a Double Exact-and-Approximate Number Representation Model. Frontiers in Human Neuroscience, 5(December), 165. http://doi.org/10.3389/fnhum.2011.00165

Norton, E. S., \& Wolf, M. (2012). Rapid Automatized Naming ( RAN ) and Reading Fluency: Implications for Understanding and Treatment of Reading Disabilities. Annual Review of Psychology, 63, 427-52. http://doi.org/10.1146/annurev-psych-120710100431

Nys, J., Ventura, P., Fernandes, T., Querido, L., Leybaert, J., \& Content, A. (2013). Does math education modify the approximate number system? A comparison of schooled and unschooled adults. Trends in Neuroscience and Education, 2(1), 13-22. http://doi.org/10.1016/j.tine.2013.01.001

Piazza, M. (2011). Neurocognitive Start-Up Tools for Symbolic Number Representations. Space, Time and Number in the Brain, 14(12), 267-285. http://doi.org/10.1016/j.tics.2010.09.008 
Piazza, M., Facoetti, A., Trussardi, A. N., Berteletti, I., Conte, S., Lucangeli, D., ... Zorzi, M. (2010). Developmental trajectory of number acuity reveals a severe impairment in developmental dyscalculia. Cognition, 116, 33-41.

http://doi.org/10.1016/j.cognition.2010.03.012

Piazza, M., Fumarola, A., Chinello, A., \& Melcher, D. (2011). Subitizing reflects visuospatial object individuation capacity. Cognition, 121, 147-153.

http://doi.org/10.1016/j.cognition.2011.05.007

Piazza, M., \& Izard, V. (2009). How humans count: numerosity and the parietal cortex. The Neuroscientist : A Review Journal Bringing Neurobiology, Neurology and Psychiatry, 15, 261-273. http://doi.org/10.1177/1073858409333073

Piazza, M., Pica, P., Izard, V., Spelke, E. S., \& Dehaene, S. (2013). Education enhances the acuity of the nonverbal approximate number system. Psychological Science, 24, 1037 43. http://doi.org/10.1177/0956797612464057

Pica, P., Lemer, C., Izard, V., \& Dehaene, S. (2004). Exact and approximate arithmetic in an Amazonian indigene group. Science (New York, N.Y.), 306(5695), 499-503. http://doi.org/10.1126/science.1102085

Praet, M., \& Desoete, A. (2014). Enhancing young children's arithmetic skills through nonintensive, computerised kindergarten interventions: A randomised controlled study. Teaching and Teacher Education, 39, 56-65. http://doi.org/10.1016/j.tate.2013.12.003

Price, G. R., Holloway, I., Räsänen, P., Vesterinen, M., \& Ansari, D. (2007). Impaired parietal magnitude processing in developmental dyscalculia. Current Biology, 17(24), $1042-1043$.

Price, G. R., Palmer, D., Battista, C., \& Ansari, D. (2012). Nonsymbolic numerical magnitude comparison: Reliability and validity of different task variants and outcome measures, and their relationship to arithmetic achievement in adults. Acta Psychologica, 140(1), 50-57. 
http://doi.org/10.1016/j.actpsy.2012.02.008

Purpura, D. J., \& Logan, J. A. R. (2015). The Nonlinear Relations of the Approximate Number System and Mathematical Language to Early Mathematics Development. Developmental Psychology, 51(12), 1717-1724.

Revkin, S. K., Piazza, M., Izard, V., Cohen, L., \& Dehaene, S. (2008). Does subitizing reflect numerical estimation? Psychological Science, 19(6), 607-614. http://doi.org/10.1111/j.1467-9280.2008.02130.x

Rivera-Batiz, F. . (1992). Quantitative literacy and the likelihood of employment among young adults in the United States. The Journal of Human Resources, 27(2), 313-328. http://doi.org/10.2307/145737

Roggeman, C., Verguts, T., \& Fias, W. (2007). Priming reveals differential coding of symbolic and non-symbolic quantities. Cognition, 105(2), 380-394. http://doi.org/10.1016/j.cognition.2006.10.004

Rousselle, L., \& Noël, M. P. (2007). Basic numerical skills in children with mathematics learning disabilities: A comparison of symbolic vs non-symbolic number magnitude processing. Cognition, 102(3), 361-395. http://doi.org/10.1016/j.cognition.2006.01.005

Rubinsten, O., \& Henik, A. (2009). Developmental Dyscalculia: heterogeneity might not mean different mechanisms. Trends in Cognitive Sciences.

http://doi.org/10.1016/j.tics.2008.11.002

Räsänen, P., Salminen, J., Wilson, A. J., Aunio, P., \& Dehaene, S. (2009). Computer-assisted intervention for children with low numeracy skills. Cognitive Development, 24(4), 450472. http://doi.org/10.1016/j.cogdev.2009.09.003

Schleifer, P., \& Landerl, K. (2011). Subitizing and counting in typical and atypical development. Developmental Science, 14, 280-291. http://doi.org/10.1111/j.14677687.2010.00976.x 
Sella, F., Tressoldi, P., Lucangeli, D., \& Zorzi, M. (2016). Training numerical skills with the adaptive videogame "The Number Race": A randomized controlled trial on preschoolers. Trends in Neuroscience and Education, 5(1), 20-29. http://doi.org/10.1016/j.tine.2016.02.002

Siegler, R. S., \& Braithwaite, D. W. (2017). Numerical Development. Annual Review of Psychology, 68(1), 187-213. http://doi.org/10.1146/annurev-psych-010416-044101

Siegler, R. S., \& Opfer, J. E. (2003). The development of numerical estimation: evidence for multiple representations of numerical quantity. Psychological Science : A Journal of the American Psychological Society / APS, 14, 237-243.

Siegler, R., \& Shrager, J. (1984). Strategy choices in addition and subtraction: How do children know what to do? In C. Origins of Cognitive Skills,.

Skagerlund, K., \& Träff, U. (2014). Development of magnitude processing in children with developmental dyscalculia: Space, time, and number. Frontiers in Psychology, 5(JUN), 1-15. http://doi.org/10.3389/fpsyg.2014.00675

Sowinski, C., LeFevre, J. A., Skwarchuk, S. L., Kamawar, D., Bisanz, J., \& Smith-Chant, B. (2015). Refining the quantitative pathway of the Pathways to Mathematics model. Journal of Experimental Child Psychology, 131, 73-93. http://doi.org/10.1016/j.jecp.2014.11.004

Starr, A., Libertus, M. E., \& Brannon, E. M. (2013). Number sense in infancy predicts mathematical abilities in childhood. Proceedings of the National Academy of Sciences of the United States of America, 110(45), 18116-20. http://doi.org/10.1073/pnas.1302751110

Träff, U., Olsson, L., östergren, R., \& Skagerlund, K. (2017). Heterogeneity of developmental dyscalculia: Cases with different deficit profiles. Frontiers in Psychology, 7(JAN). http://doi.org/10.3389/fpsyg.2016.02000 
Uittenhove, K., Thevenot, C., \& Barrouillet, P. (2016). Fast automated counting procedures in addition problem solving: When are they used and why are they mistaken for retrieval? Cognition, 146, 289-303. http://doi.org/10.1016/j.cognition.2015.10.008

van der Sluis, S., de Jong, P. F., \& van der Leij, A. (2004). Inhibition and shifting in children with learning deficits in arithmetic and reading. Journal of Experimental Child Psychology, 87, 239-266. http://doi.org/10.1016/j.jecp.2003.12.002

van Garderen, D. (2006). Spatial Visualization, Visual Imagery, and Mathematical Problem Solving of Students With Varying Abilities. Journal of Learning Disabilities, 39(6), 496-506. http://doi.org/10.1177/00222194060390060201

Verdine, B. N., Golinkoff, R. M., Hirsh-Pasek, K., \& Newcombe, N. S. (2017). Spatial skills, their development, and their links to mathematics. Monographs of the Society for Research in Child Development, 82(1), 1-150. http://doi.org/10.1111/mono.12280 Von Aster, M. (2000). Developmental cognitive neuropsychology of number processing and calculation: Varieties of developmental dyscalculia. European Child and Adolescent Psychiatry, 9(SUPPL. 2). http://doi.org/10.1007/s007870070008

von Aster, M. G., \& Shalev, R. S. (2007). Number development and developmental dyscalculia. Developmental Medicine \& Child Neurology, 49(11), 868-873. http://doi.org/10.1111/j.1469-8749.2007.00868.x

Vukovic, R. K., \& Lesaux, N. K. (2013a). The language of mathematics: Investigating the ways language counts for children's mathematical development. Journal of Experimental Child Psychology, 115(2), 227-244. http://doi.org/10.1016/j.jecp.2013.02.002

Vukovic, R. K., \& Lesaux, N. K. (2013b). The relationship between linguistic skills and arithmetic knowledge. Learning and Individual Differences, 23(1), 87-91. http://doi.org/10.1016/j.lindif.2012.10.007

Wang, Y., Geng, F., Hu, Y., Du, F., \& Chen, F. (2013). Numerical processing efficiency 
improved in experienced mental abacus children. Cognition, 127(2), 149-158. http://doi.org/10.1016/j.cognition.2012.12.004

Willburger, E., Fussenegger, B., Moll, K., Wood, G., \& Landerl, K. (2008). Naming speed in dyslexia and dyscalculia. Learning and Individual Differences, 18, 224-236. http://doi.org/10.1016/j.lindif.2008.01.003

Wilson, A. J., \& Dehaene, S. (2007). Number sense and developmental dyscalculia. In Human behavior, learning, and the developing brain: Atypical development. (pp. 212238). Retrieved from http://proxy-

remote.galib.uga.edu/login?url=http://search.ebscohost.com/login.aspx direct=true $\& \mathrm{db}=$ psyh\&AN=2007-04220-009\&site=eds-live

Wilson, A. J., Dehaene, S., Dubois, O., \& Fayol, M. (2009). Effects of an Adaptive Game Intervention on Accessing Number Sense in Low-Socioeconomic Status Kindergarten Children. Mind, Brain, and Education, 3(4), 224-234.

Wilson, A. J., Revkin, S. K., Cohen, D., Cohen, L., \& Dehaene, S. (2006). An open trial assessment of "The Number Race", an adaptive computer game for remediation of dyscalculia. Behavioral and Brain Functions : BBF, 2, 20. http://doi.org/10.1186/17449081-2-19

Wynn, K. (1992). Addition and subtraction by human infants. Nature, 358(6389), 749-750. http://doi.org/10.1038/358749a0

Zorzi, M., Stoianov, I., \& Umiltà, C. (2005). Computational Modeling of Numerical Cognition. In Handbook of mathematical cognition (Vol. 19, pp. 67-84). 


\section{Papers}

The papers associated with this thesis have been removed for copyright reasons. For more details about these see:

http:// urn.kb.se/ resolve?urn=urn:nbn:se:liu:diva-144196 


\section{LINKÖPING STUDIES IN BEHAVIOURAL SCIENCE}

180. BERGMAN NORDGREN, LISE. Individually tailored internet-based cognitive behavioural therapy for anxiety disorders. 2013. ISBN: 978-917519-459-2

181. FREJD, PETER. Modes of Mathematical Modelling. An Analysis of how modelling is used and interpreted in and out of school settings. 2014. ISBN: 978-91-7519-414-1

182. AMAN, ROBERT. Impossible Interculturality? Education and the Colonial Difference in a Multicultural World. 2014. ISBN: 978-91-7519-348-9

183. NYLANDER, ERIK. Skolning i jazz. Värde, selektion och studiekarriär vid folkhögskolornas musiklinjer. 2014. ISBN: 978-91-7519-347-2

184. GRADIN FRANZÈN, ANNA. Disciplining freedom: Treatment dilemmas and subjectivity at a detention home for young men. 2014. ISBN: 978-917519-344-1

185. ENGSTRÖM, ANNIKA. Lärande samspel för effektivitet. En studie av arbetsgrupper i ett mindre industriföretag. 2014. ISBN:978-91-7519-345-8

186. ELWÉR, ÅSA. Early Predictors of Reading Comprehension Difficulties. 2014. ISBN: 978-91-7519-281-9

187. LARSON, NICLAS. Matematikämnet och stadiebytet mellan grundskolan och gymnasieskolan. En enkät- och klassrumsstudie. 2014. ISBN: 978-917519-196-6

188. LY, HOA. Use of a Smartphone Application in the Treatment of Depression - The New Wave of Digital Tools for Psychological Treatment. 2015. ISBN: 978-91-7519-136-2

189. HANSSON, PER-OLOF. New ways of learning. Participatory action research and Kenyan runners' appropriation of smartphones to improve their daily lives and participation in m-learning. 2015. ISBN: 978-91-7519124-9

190. BOLLDÈN, KARIN. Online teaching practices. Sociomaterial matters in higher education settings. 2015. ISBN: 978-91-7519-123-2

191. MALMQUIST, ANNA. Pride and Prejudice. Lesbian families in contemporary Sweden. 2015. ISBN: 978-91-7519-087-7 
192. AVBY, GUNILLA. Evidence in Practice. On Knowledge Use and Learning in Social Work. 2015. ISBN: 978-91-74519-088-4

193. FORSBERG, CAMILLA. Students’ Perspectives on Bullying. 2016. ISBN: 978-91-7685-874-5

194. MUHRMAN, KAROLINA. Inget klöver utan matematik. En studie av matematik i yrkesutbildning och yrkesliv. 2016. ISBN: 978-91-7685-851-6

195. SKAGERLUND, KENNY. Magnitude Processing in Developmental Dyscalculia. A Heterogeneous learning disability with different cognitive profiles. 2016. ISBN: 978-91-7685-831-8

196. EKEBLAD, ANNIKA. A Randomized Trial of Interpersonal Psychotherapy and Cognitive Behavioral Therapy for Major Depressive Disorder Predictors of process and outcome. 2016. ISBN: 978-91-7685-803-5

197. MÅNSSON, KRISTOFFER N.T. Restructuring the Socially Anxious Brain. Using magnetic resonance imaging to advance our understanding of effective cognitive behaviour therapy for social anxiety disorder. 2016. ISBN: 978-91-7685-688-8

198. SILFVERNAGEL, KRISTIN. Individually tailored internet-based cognitive behavioural therapy for adolescents, young adults and older adults with anxiety. 2017. ISBN: 978-91-7685-566-9

199. ELOFSSON, JESSICA. Children's early mathematics learning and development. Number game interventions and number line estimations. 2017. ISBN: 978-91-7685-517-1

200. ÅHLFELDT, EMANUEL. Hållbart utvecklingsarbete i vård och omsorg. Ett institutionellt perspektiv på projekt i en professionell och byråkratisk kontext. 2017. ISBN: 978-91-7685-445-7

201. VERNMARK, KRISTOFER. Therapeutic alliance and different treatment formats when delivering internet-based CBT for depression. 2017. ISBN: 978-91-7685-436-5

202. FRANKL, MY. Psychotherapy for Substance Use Disorder - the importance of affects. 2017. ISBN: 978-91-7685-429-7

203. ABDULLA, AFRAH. Readiness or resistance? - Newly arrived adult migrants' experiences, meaning making, and learning in Sweden. 2017. ISBN: 978-91-7685-428-0 